\title{
EL SECTOR DE LA GENERACIÓN DE LA ENERGÍA EN ARAGÓN: RELEVANCIA, EVOLUCIÓN E INVISIBILIDAD DE SUS VESTIGIOS ANTE LOS PODERES PÚBLICOS
}

\author{
The Energy Generation Sector in Aragon: Relevance, Evolution \\ and Invisibility of its Vestiges for the Public Authorities
}

\author{
Ignacio J. SORLI LASHERAS \\ Universidad de Zaragoza \\ nachosolas@gmail.com
}

\section{Resumen}

Los procesos de industrialización provenientes de la primera Revolución Industrial alcanzaron a España y a Aragón con un importante retraso. Dentro del amplio abanico de sectores industriales, el de la generación energética resultó indispensable para acelerar los procesos productivos y promover mejoras tecnológicas. En Aragón, al igual que en otros lugares, las estructuras nacidas del sector energético modificaron paisajes y dinamizaron el territorio en el que se ubicaron, constituyendo una fuente de riqueza y modo de vida para sus gentes. Muchas de esas estructuras generadoras de energía ya cerraron sus puertas, pero, en la actualidad, forman parte de un rico Patrimonio industrial estudiado por disciplinas como la Arqueología industrial. Lamentablemente, en Aragón, los poderes públicos encargados de su protección y reutilización mantienen sumido en un profundo abandono a los vestigios industriales relacionados con la generación energética a pesar de su evidente importancia histórica, económica y social.

Palabras clave: industrialización, sector energético, patrimonio industrial, inventarios, protección patrimonial, abandono patrimonial. 


\section{Abstract}

Industrialization processes from the first Industrial Revolution reached Spain and Aragon with a significant delay. Within the wide range of industrial sectors, energy generation was essential to accelerate production processes and promote technological improvements. In Aragon, as in other places, structures born from the energy sector modified landscapes and energized the territory in which they were located, constituting a source of wealth and way of life for its people. Many of these energygenerating structures have already closed their doors but, at present, they are part of a rich industrial heritage studied by disciplines such as industrial archeology. Unfortunately, in Aragon, the public authorities in charge of their protection and reuse keep industrial vestiges related to energy generation in deep abandonment despite their obvious historical, economic and social importance.

Key words: industrialization, energy sector, industrial heritage, patrimonial inventory, patrimonial protection, patrimonial abandonment.

\section{INTRODUCCIÓN}

El sector de la producción energética ha sido uno de los ámbitos industriales más relevantes en la comunidad autónoma de Aragón. La proliferación de plantas generadoras desde finales del siglo xix atendió a importantes factores geográficos que indicaban cuales eran las ubicaciones más beneficiosas según el tipo de generación escogido. De esta manera, en Aragón se impusieron mayoritariamente dos modelos que han llegado hasta la actualidad. El primero de ellos, la generación hidráulica, aprovechó los cauces de ríos y saltos de agua. En este caso, la provincia de Huesca rápidamente adquirió una posición predominante debido, sobre todo, a sus comarcas altopirenaicas que vieron cómo se multiplicaban en su interior numerosas plantas productoras. El segundo modelo es la producción energética térmica, es decir, aquella que proviene de elementos fósiles combustibles. Este hecho implicó que las plantas generadoras buscaran localizaciones ventajosas en cuanto a accesibilidad de los materiales combustibles provenientes de actividades extractivas. De esta manera, la ligazón creada entre minería y generación de energía adquirió una gran relevancia y motivó el surgimiento de novedosos paisajes industriales. En definitiva, podemos decir que el sector de la producción energética - fuera cual fuera su tipología- modificó el entorno, dinamizó y articuló territorios, produjo 
movimientos de personas y significó una fuente de vida y de riqueza para los habitantes del lugar.

En la actualidad muchos de estos elementos industriales de generación energética han ido cayendo en desuso y abandono, tras las operaciones de cierre por parte de sus propietarios - generalmente entidades privadas con objetivos principalmente económicos y comerciales. En Aragón, las estructuras que han quedado sobre el terreno forman parte de un rico patrimonio industrial que no ha sido objeto de estudios eficaces hasta finales de los 90 del pasado siglo, momento en el que comenzó a nacer una concienciación y preocupación por la preservación de este tipo de patrimonio. Se introdujeron así en Aragón las premisas y las actividades de una novedosa disciplina en esa región: la arqueología industrial.

Sin embargo, a pesar de contar con décadas de trabajo en torno al $\mathrm{Pa}-$ trimonio industrial aragonés, los resultados no son nada aceptables en cuanto a las estructuras de producción energética que tanta relevancia e impacto socioeconómico tuvieron en el pasado. Hoy en día en Aragón, los vestigios industriales procedentes de la generación energética continúan sin ser atendidos por los poderes públicos correspondientes, negando cualquier tipo de protección jurídica de base que permitiría, al menos, comenzar su recuperación.

El presente trabajo persigue un triple objetivo. En primer lugar, identificar cómo y cuándo surgió en Aragón la sensibilización en torno a la defensa del patrimonio industrial. En segundo lugar, analizar cuáles fueron los primeros trabajos en torno al patrimonio cultural e industrial aragonés, incluyendo el desarrollo de su marco legal. En tercer y último lugar, se estudia la importancia del sector de la generación energética en Aragón que, pese a su gran relevancia en el pasado industrial aragonés, carece de protección patrimonial por parte de las administraciones públicas.

En cuanto a la metodología seguida y la estructura del trabajo, se ha elaborado un breve estado de la cuestión en torno al surgimiento y evolución de la Arqueología industrial en Aragón, unido a la definición del Patrimonio industrial, dos conceptos que a menudo se utilizan erróneamente. Para ello se ha realizado una aproximación a nivel mundial y a nivel nacional - para llegar al nivel regional - en torno al surgimiento de la concienciación en cuanto a la protección de los vestigios industriales.

Seguidamente se analizan los trabajos que se han desarrollado en torno al patrimonio cultural aragonés, partiendo de la base jurídica necesaria para legitimar cualquier acción sobre dicho patrimonio. Posteriormente, 
se ha efectuado un amplio repaso en torno al tratamiento que se le han dado en Aragón a los vestigios industriales (como parte del patrimonio cultural) desde los inicios de las labores de inventariado hasta la constitución de las potentes y actuales herramientas y bases de datos; hablamos de los ficheros del Sistema de información del patrimonio cultural aragonés (SIPCA) o el catálogo de bienes protegidos de la Dirección de Cultura y Patrimonio del Gobierno de Aragón.

Por último, tras estudiar la gran importancia que el sector de la generación de la energía ha tenido en el pasado industrial de Aragón se da paso al análisis de la visibilidad de los vestigios procedentes del sector energético aragonés en los correspondientes registros al efecto, así como sus niveles de protección jurídica, si es que existen.

Las fuentes utilizadas han sido de diversa índole. En primer lugar, se ha trabajado sobre bibliografía de referencia en arqueología industrial y patrimonio industrial, tanto a nivel internacional, como nacional y regional. Igualmente se ha contado con bibliografía especifica de la hjistoria económica de Aragón, necesaria para el análisis de la relevancia del sector energético en esa región. Otros textos consultados son los documentos normativos que ofrecen la importante ventaja de poder ser revisados mediante Internet, estando siempre actualizados.

En la tarea de búsqueda y localización bibliográfica han sido de gran ayuda los soportes digitales permitiendo en alguno de los casos el acceso inmediato a los documentos. En este sentido, se ha utilizado el repertorio bibliográfico Dialnet así como el servicio Alcorze de la Universidad de Zaragoza, entre otras bases de datos bibliográficas.

Además de todo ello, la ayuda de otras fuentes informáticas ha sido fundamental, especialmente los inventarios telemáticos de vestigios culturales, como el Sistema de información del patrimonio cultural aragonés (SIPCA), así como los catálogos patrimoniales que elaboran las diferentes consejerías de cultura de las distintas comunidades autónomas, especialmente las de País Vasco, Andalucía y Aragón.

Por último, ha sido muy importante la consulta informática de sitios web de algunas de las asociaciones más importantes en cuanto a la defensa del patrimonio industrial o de blogs dedicados a recopilación de fotografías de algunos de los vestigios estudiados, así como de entidades privadas, como ENDESA. Todas las fuentes utilizadas han sido consignadas en el apartado de fuentes bibliográficas y otros recursos. 


\section{ESTADo DE LA CUESTIÓN}

Es frecuente observar cómo los conceptos de patrimonio industrial y arqueología industrial son confundidos y utilizados indistintamente. En una primera aproximación podemos indicar que el primero de ellos hace referencia a los vestigios materiales o inmateriales que se conservan provenientes del mundo del trabajo, más concretamente de las sociedades industriales. Por su parte, el segundo término describe una disciplina que, valiéndose de otras auxiliares, analiza y estudia el pasado industrial de un lugar y de las sociedades que lo habitaron. Analicemos con mayor detenimiento el surgimiento de la concienciación por la defensa del patrimonio industrial asociada a la génesis de una nueva disciplina: la arqueología industrial.

Desde la aparición de la preocupación por la conservación de los restos materiales ligados a la industrialización - cuyo hito inicial se sitúa en 1962 con la destrucción de la Euston Station de Londres - el concepto de patrimonio industrial como objeto de estudio de la Arqueología industrial ha ido configurándose, siendo en el último tercio del siglo xx cuando se impulsó notablemente la actividad en torno a su definición.

En este sentido, en la década de los años 90 podemos encontrar las primeras definiciones de patrimonio industrial. La Asamblea Parlamentaria europea editó en 1990 un texto sobre recomendaciones relativas a la protección del patrimonio técnico, industrial y de ingeniera civil en el ámbito europeo, integrándolo directamente en el patrimonio histórico de $\mathrm{Eu}$ ropa. En este documento se introdujo una importante cuestión ya que, además de los restos materiales, el texto incluyó el aspecto inmaterial de los vestigios técnicos, indicando que «El Patrimonio técnico, industrial y de ingeniería civil no se constituye solo de edificios, monumentos u objetos, sino también del entorno físico, como un conjunto de conocimientos, de técnicas y de forma de vida». ${ }^{1}$

Más adelante, en el año 2003, la asamblea nacional del The International Committee for the Conservation of the Industrial Heritage (TIC$\mathrm{CIH})$, en la que se debatió el término conceptual de patrimonio industrial, aprobó el texto de la Carta Nizhny Tagil, constituyendo el primer borrador de referencia internacional en cuanto a la protección y conser-

1 Este documento puede consultarse en su versión inglesa en: $<$ https://www.euskadi.eus/contenidos/informacion/manifiestos_patrimonio/es_8658/adjuntos/DOC47.pdf $>$ [consulta: 20-6-2020] 
vación del patrimonio industrial. En este documento se definió el patrimonio industrial como:

Los restos de la cultura industrial que poseen un valor histórico, tecnológico, social, arquitectónico o científico. Estos restos consisten en edificios y maquinaria, talleres, molinos y fábricas, minas y sitios para procesar y refinar, almacenes y depósitos, lugares donde se genera, se transmite y se usa energía, medios de transporte y toda su infraestructura, así como los sitios donde se desarrollan las actividades sociales relacionadas con la industria, tales como la vivienda, el culto religioso o la educación. ${ }^{2}$

Además de esta definición, la Carta Nizhny Tagil incluyó una descripción de los distintos tipos de valores del patrimonio industrial - como el valor histórico, el social o el cultural - así como la imperiosa necesidad de protección, conservación y de trabajos de inventariado, registro e investigación previos.

Aproximándonos a nuestros ámbitos nacionales y regionales, podemos observar cómo la Ley 16/1985, de 25 de junio de Patrimonio Histórico Español - cuya última actualización data de marzo de 2019- indica en su artículo 1.2.

Integran el Patrimonio Histórico Español los inmuebles y objetos muebles de interés artístico, histórico, paleontológico, arqueológico, etnográfico, científico o técnico. También forman parte del mismo el patrimonio documental y bibliográfico, los yacimientos y zonas arqueológicas, así como los sitios naturales, jardines y parques, que tengan valor artístico, histórico o antropológico. ${ }^{3}$

Como vemos, se nombra el interés científico o técnico de los restos, pero no aparece la característica de industrial.

En cuanto al marco jurídico aragonés, tal y como analizaremos más adelante, la norma de referencia es la Ley 3/1999, de 10 de marzo de Patrimonio Cultural Aragonés en la que igualmente se habla de Patrimonio cultural aragonés en su artículo 2 bajo el interés técnico y científico. No obstante, en el artículo 73 de esta norma se define el patrimonio de carácter industrial indicándonos que "Constituyen el Patrimonio de carácter industrial aquellos bienes de carácter etnográfico que forman parte del pasa-

2 La Carta Nizhny Tagil puede consultarse desde la página web del TICCIH en $<$ http://www. ticcih.es/wp-content/uploads/2012/03/nizhny-tagil-charter-sp.pdf> [consulta: 20-6-2020]

3 La Ley 16/1985, de 25 de junio de Patrimonio Histórico Español en la Ley 16/1985, de 25 de junio de Patrimonio Histórico Español [consulta: 20-06-2020] 
do tecnológico, productivo e industrial aragoneses y son susceptibles de ser estudiados con metodología arqueológica».

En torno a esta cuestión, Pilar Biel Ibáñez indica la posible falta de precisión del legislador al reunir en la misma definición los conceptos de etnografía y de arqueología. ${ }^{4}$ El primero de ellos efectúa una descripción de las actividades y manifestaciones culturales de los diferentes pueblos y razas, especialmente en culturas primitivas. El segundo, puede llevarnos a pensar con facilidad en la disciplina que estudia los restos materiales de las culturas antiguas mediante la excavación del terreno. Por ello, según Biel Ibáñez, parece que el artículo normativo afecta especialmente al Patrimonio industrial legado por las sociedades anteriores a la revolución industrial.

Por último, podemos incluir la definición de patrimonio industrial ofrecida por el Ministerio de Cultura y Deporte español en la actualidad:

Se entiende por Patrimonio industrial el conjunto de los bienes muebles, inmuebles y sistemas de sociabilidad relacionados con la cultura del trabajo que han sido generados por las actividades de extracción, de transformación, de transporte, de distribución y gestión generadas por el sistema económico surgido de la «revolución industrial». ${ }^{5}$

El mencionado ministerio elaboró en el año 2001 un Plan nacional de Patrimonio industrial en el que se indica, además de la necesidad del diseño de un plan, el ámbito de actuación (tanto físico como cronológico) y la necesidad de un soporte legal que sustente las actuaciones sobre los vestigios industriales. Este Plan nacional definió el Patrimonio industrial como

El conjunto de elementos de explotación industrial, generado por las actividades económicas de cada sociedad. Este patrimonio responde a un determinado proceso de producción, a un concreto sistema tecnológico, caracterizado por la mecanización, dentro de una manifestación de relación social capitalista. ${ }^{6}$

Este documento amplía la terminología definiendo el 'bien industrial' como cada uno de los elementos que componen el patrimonio industrial, dentro de la categoría de bienes inmuebles.

4 María Pilar Biel Ibáñez, «El patrimonio industrial en Aragón. Situación actual», en María Pilar Biel Ibáñez (coord.), Jornadas de patrimonio industrial y la obra pública de Zaragoza, Zaragoza, Gobierno de Aragón, 2007, p. 261.

5 Ministerio de Cultura y Deporte, <http://www.culturaydeporte.gob.es/planes-nacionales/ inicio-recuperar.html $>$ [consulta: $1 / 6 / 2020$ )

6 Este documento puede consultarse en <www.culturaydeporte.gob.es $>$ dam $>$ documento-base2001> [consulta: 15-6-2020] 
Llama la atención que estas dos últimas definiciones de patrimonio industrial remarcan el ámbito temporal de los restos industriales, bien indicando que se refiere a los surgidos tras la revolución industrial, o bien los relacionados con una manifestación social capitalista.

Por su parte, la arqueología industrial nació como disciplina en los años 1960 en Inglaterra directamente ligada con su gran pasado industrial. El término de arqueología industrial fue establecido por Donald Dudley, miembro de la Universidad de Birmingham, en 1950 y apareció en una fuente impresa por primera vez en el año 1955 en un artículo de la revista The Amateur Historian, firmado por Michael Rix, colega de Dudley. En este sentido Rix simplemente se refirió al término en relación a un estudio de los restos industriales, sin abordar el concepto ni la metodología de la disciplina.

Rafael Aracil Martí señala una acción concreta como punto de partida de esta disciplina: la destrucción de la Euston Station de Londres en 1962, construida entre 1835 y 1839. Esta demolición provocó diversas corrientes de opinión de historiadores y científicos a la que se sumó el eco popular para la defensa del patrimonio industrial británico. ${ }^{7}$ Sin embargo, casi un siglo antes ya se dieron algunos pasos previos, como los de Isaac Fletcher, ${ }^{8}$ autor en 1878 de un estudio titulado «La arqueología del comercio del carbón de West Cumberland».

La aparición de este nuevo campo de investigación trajo consigo una serie de cuestiones como cuál debería ser la metodología científica aplicada, los límites de su estudio e investigación o los novedosos conceptos directamente asociados con la disciplina como, por ejemplo, el de «monumento industrial». La Inspección de Antiguos Monumentos del Ministerio de Trabajo inglés aceptó la siguiente definición para referiste a monumento industrial.

7 Rafael Aracil Martí, «La investigación en arqueología industrial» en I Jornadas sobre la protección y protección y revalorización del patrimonio industrial, Bilbao, Departamento de Cultura del Gobierno Vasco, 1982, p. 17.

8 Nacido en el año 1827 en Cumberland (Inglaterra) Isaac Fletcher fue maestro de forja y, en la última etapa de su vida, político liberal inglés presente en la Cámara de los Comunes entre 1868 y 1879, año en que murió. Fue un personaje emprendedor y manifestó una importante preocupación por la economía de su tierra. Igualmente se interesó por la Historia y dentro de ella, la historia de las industrias de Cumberland. 
Un monumento industrial es cualquier edificio o estructura fija, especialmente del periodo de la revolución industrial que, o bien sola o asociada con equipo de plantas primarias, ilustre el principio y desarrollo de los procesos técnicos e industriales incluyendo los medios de comunicación. ${ }^{9}$

En cuanto al objeto de estudio de esta reciente disciplina, el arqueólogo industrial de la Universidad de Bath, Angus Buchanan definió su contenido como

[...] un campo de estudio referido a la investigación, estudio, clasificación y, en algunos casos, conservación de los monumentos industriales, aspirando también a hacer que se aprecie el significado de tales monumentos en el contexto de la historia social y la tecnología. ${ }^{10}$

Es importante indicar cómo Buchanan incluye en su definición de la materia a estudio por esta disciplina la necesaria valoración que debe hacerse del patrimonio industrial desde la óptica de su valor histórico y social, no contemplando únicamente la dimensión material y física de recuperación y reutilización del bien. Además de ello, Buchanan incluyó en el catálogo de elementos y bienes susceptibles de ser tratados como monumentos industriales una amplia gama de objetos relativos a industrial mineras, siderurgia, textil, química, agrícola y de producción de energía. Sumado a todo ello se presentan los transportes - puertos, carreteras canales o ferrocarriles, por ejemplo- así como elementos comunitarios y de servicios - alcantarillado, red de aguas - con la condición para todos ellos que deben estar en desuso o en vías de estarlo, así como desfasados tecnológicamente. ${ }^{11}$

Otro autor de referencia que contribuyó a definir la arqueología industrial es Keneth Hudson, quien la consideró como el descubrimiento, catalogación y el estudio de los vestigios físicos de las comunicaciones y del pasado industrial. ${ }^{12}$ Sin embargo, según nos hace notar Aracil Martí, Hudson fue más allá del mero trabajo con los restos materiales que pertenecieron a un pasado industrial, interesándose también por la propia mentalidad de los seres humanos que trabajaron en aquellas instalaciones y vivieron en los

9 Arthur Raistrik, Industrial Archaeology, Suffolk, Eyre Methuen, 1972, p. 2.

10 Agnus Buchanan, Industrial Archaeology in Britain, London, Penguin Books, 1982, p. 26, dentro de los estudios de Jiménez Zorzo, Francisco Javier (1987), La industrialización en Aragón. La fundición Averly de Zaragoza. Zaragoza, Gobierno de Aragón, 1987, pp.14-15.

11 Francisco Javier Jiménez Zorzo, 1987, p.26.

12 Rafael Aracil Martí, 1982, p.19 
paisajes y las ubicaciones industriales. Así pues Hudson se planteó si no sería mejor sustituir el termino de Arqueología industrial por el de Historia del Trabajo; cuestión a la que se sumó el propio Aracil al alinearse con estos planteamientos de Hudson y de Aldo Castellano, quien definió la Arqueología industrial como «la antropología histórica de la sociedad industrial», ${ }^{13}$ en una clara referencia a la necesidad de estudiar no solo los restos materiales, sino también la historia cultural y los cambios de mentalidad experimentados por las sociedades posteriores a la industrialización.

En España, Miguel Ángel Álvarez Areces establece que la arqueología industrial es

El método interdisciplinario para el estudio de evidencia, material o inmaterial, de documentos, artefactos, estratigrafía y estructuras, asentamientos humanos, terrenos naturales y urbanos, creados por procesos industriales o para ellos, utilizando las herramientas de investigación más adecuadas para entender mejor el pasado y el presente industrial. ${ }^{14}$

Como podemos observar, en la extensa definición anterior aparecen una serie de caracteres clave. Por un lado, la necesidad de la interdisciplinariedad; esto es, el apoyo de la arqueología industrial en otras ciencias o especialidades. Por otro lado, Álvarez Areces nos habla de un mejor conocimiento y entendimiento del pasado y del presente industrial, dejando la puerta abierta a que la arqueología industrial pueda trabajar sobre objetos industriales todavía en su uso original.

Paralelamente, fueron surgiendo diversas asociaciones con dimensión multinacional cuyo objetivo es, entre otros, el de defender el patrimonio industrial. Entre ellas destaca The International Committee for the Conservation of the Industrial Heritage (TICCIH) que se fundó en Inglaterra en 1972 como fruto de la primera conferencia para la protección del Patrimonio industrial celebrado en Ironbridge (Inglaterra). Se trata de un organismo internacional que actualmente posee sus diferentes divisiones nacionales en diferentes países. Sus principales objetivos se sintetizan en investigar y compartir información acerca de las actuaciones sobre el $\mathrm{Pa}$ trimonio industrial, así como su conservación, reutilización o puesta en valor de otros modos que garanticen su preservación como vestigios del pasado industrial.

13 Rafael Aracil Martí, 1982, p. 23.

14 Miguel Ángel Álvarez Areces, Arqueología industrial. El pasado por venir. Gijón, CICEES, 1995, p.15. 
En el ámbito español, la aparición de la preocupación por la protección de los restos arqueológicos industriales surgió con retraso respecto a los países europeos pioneros - Inglaterra, Francia o Alemania-. Las causas de ello son, sin duda, el tardío acceso del país a los procesos de industrialización y desarrollo económico y, posteriormente, la generación de un tejido industrial heterogéneo..$^{15}$ Esto provocó que las zonas industriales fueran mucho más localizadas - como es el caso de Cataluña, País Vasco y puntos mineros al sur, como Almadén o Riotinto, entre otros. Debido a la presencia de dichos materiales industriales, estas regiones fueron las primeras en manifestar su preocupación por los restos, así como su puesta en valor como elementos potencialmente reutilizables para otros usos después de su trasformación.

Desde la década 1980 las universidades, los museos y los centros de investigación, todos ellos apoyados por entidades públicas o privadas, comenzaron a comprender la necesidad de una actuación basada en la catalogación, protección y estudio de los edificios y equipos industriales, además de acometer la búsqueda de una posible reutilización de ellos.

En este contexto, los estudios académicos fueron incrementándose notablemente. Uno de los precursores de esta disciplina en España es Rafael Aracil Martí, promotor de las I Jornadas sobre Protección y Revalorización del Patrimonio industrial celebradas en el año 1982 en Bilbao. Aracil sentó las bases metodológicas de la disciplina en nuestro país. Su principal trabajo - y pionero en la materia - es la Arqueología industrial en Alcoy, publicado en 1981.

Tras Aracil, aparecieron importantes trabajos de síntesis como el de Esteban Sarasa Sánchez «La arqueología industrial: estudio históricoarqueológico del pasado industrial español» de 1984 en el que incide en el inicial abandono de la Arqueología - como ciencia auxiliar de la Historia - hacia el campo de la industria. Además, presenta la arqueología industrial como una materia interdisciplinar cuyo objeto pueden ser los vestigios no solo postindustriales sino también preindustriales. Xavier Barral i Altet publicó en 1989 su «Arqueología industrial o Arqueología del mundo moderno y contemporáneo» donde plantea la problemática de la terminología de la disciplina, sus límites y su necesaria interdisciplinariedad. Tras estos textos apareció una obra global y

15 Miguel Izard i Llorens, «Arqueología, dependencia y subdesarrollo: el caso catalán» en I Jornadas sobre la protección... op.cit., pp. 114-122. 
con una carga teórica muy importante: se trata de la Arqueología industrial. Notas para un debate, editado en 1991 fruto del trabajo de $\mathrm{M}^{\mathrm{a}}$ Dolores Ramos Palomo, Concepción Campos Luque y $\mathrm{M}^{\mathrm{a}}$ Ángeles Martín Reyes. En ella se analiza el concepto y metodología de la disciplina, así como el estudio de su aplicación en Europa para pasar a estudiar el caso particular de Andalucía.

A partir de la década de 1990 podemos decir que la arqueología industrial española se iba aproximando a la de nuestros vecinos europeos. Se consolidó la preocupación por las actuaciones encaminadas a inventariar, estudiar y proteger los vestigios industriales. La bibliografía en torno a esta disciplina también aumentó considerablemente. Más adelante, en 2007, Miguel Ángel Álvarez Areces publicó su Arqueología industrial. El pasado por venir, donde trabaja las perspectivas de conservación del patrimonio industrial.

Finalmente, podemos indicar que la investigación y actuaciones de la arqueología industrial contemplan un panorama irregular con claras diferenciaciones entre países, casi en analogía con la evolución que mostró la industrialización fruto de la Revolución Industrial. En Europa, Inglaterra es el país que más ha desarrollado esta disciplina junto con algunas de las naciones occidentales (Francia, Alemania). Sin embargo, se aprecia un retraso en su desarrollo en la Europa mediterránea, tal y como señala Francisco Javier Jiménez Zorzo, quizá eclipsada por la riqueza arquitectónica clásica que mantuvo la atención de las disciplinas arqueológicas, incluso después de que ya se conociera la importancia de actuar sobre el patrimonio industrial. ${ }^{16}$

Al igual que los procesos de industrialización no fueron homogéneos en todo el territorio nacional, tal y como se ha indicado, el acceso de las diferentes comunidades autónomas a la arqueología industrial observó también importantes diferencias. Se puede apreciar una relación directa entre el acceso a la industrialización y la atención a los vestigios que se originaron a raíz de aquella. En este sentido, comunidades autónomas como País Vasco o Cataluña fueron pioneras en los procesos de industrialización y también precursoras en el estudio y protección de los restos industriales. Siguiendo esta premisa, Aragón accedió de una manera tardía a la ola industrialización y, efectivamente, también a la concienciación en la protección de los vestigios que generó.

16 Francisco Javier Jiménez Zorzo, 1987, p. 16. 
Durante la década de 1970 y 1980 la industria aragonesa era todavía objeto de estudios históricos y económicos por parte de la Facultad de Ciencias Económicas y Empresariales de la Universidad de Zaragoza. Quedaban alejados de una visión arqueológica y de conservación del patrimonio. Se pueden destacar publicaciones periódicas como los «Cuadernos aragoneses de economía» de la Universidad de Zaragoza o la Introducción a la economía de la región aragonesa de José Antonio Biescas, publicado en el año 1977.

Con posterioridad, en el marco legal tras la transición política española, la comunidad autónoma de Aragón evolucionó en consonancia con el resto de comunidades dentro del escenario legislativo común fijado por la Ley de Patrimonio Histórico Español (LPHE). La Dirección General de Cultura y Patrimonio, bajo convenio con la Universidad de Zaragoza y con financiación del Gobierno de Aragón, las diputaciones provinciales y las comarcas, fue la encargada de elaborar el Inventario del Patrimonio industrial y la obra pública de Aragón, Inventario inédito (2004-2009), ${ }^{17}$ fundamental para el desarrollo de la disciplina. Este inventario abordó cinco áreas diferenciadas: arquitectura industrial, maquinaria y objetos, infraestructuras de comunicaciones, patrimonio hidráulico y archivos de empresa. Actualmente, ha recibido numerosas revisiones y ampliaciones y ofrece información sobre los bienes analizados - historia, construcción y actividad, situación actual, fotografías. Una de las principales responsables de estos trabajos es Pilar Biel Ibáñez, profesora del departamento de Historia del Arte de la Universidad de Zaragoza y actualmente miembro la Junta Directiva del Comité Internacional para la conservación y defensa del patrimonio industrial en su división española (TICCIH).

Sobre esta autora encontramos además una importante obra homónima que sintetiza lo que fue su tesis doctoral defendida en 2001 titulada Zaragoza y la industrialización: la arquitectura industrial en la capital aragonesa entre 1875 y 1936. Este trabajo analiza los procesos de industrialización de Zaragoza en el ámbito español y aragonés. Igualmente estudia la diferente evolución industrial y su diversificación por sectores, así como su integración en la sociedad de la época, inmersa esta en irreversibles procesos de crecimiento urbano. La obra contiene un importante catálogo de

17 Puede consultarse la noticia referente a los trabajos de este inventario en la web del SIPCA: $<\mathrm{http}$ ://www.sipca.es/noticias/noticia.jsp?id_noticia=154\&vieneDe=lista\#.Xh4BS_5Ki1s $>$ [consulta: 10-1-2020] 
vestigios en función de los sectores industriales en los que se encuadran (alimentación, metalurgia, química, cerámica y vidrio, textil, tecnología de la piel, madera y papel, artes gráficas, electricidad, producción artística y otros sectores) proporcionando una enorme cantidad de datos sobre los restos arqueológicos industriales.

Igualmente, María Pilar Biel coordinó junto a Javier Jiménez Zorzo - ambos pueden considerarse pioneros de la disciplina en Aragón - en 2005 el importante trabajo Patrimonio industrial de la provincia de Zarago$z a$, que analiza los restos industriales atendiendo a una división comarcal. Jiménez Zorzo desarrolló su tesis doctoral, bajo dirección de Manuel García Guatas, publicada en 1992 bajo el título Arqueología industrial en Aragón: Arte, Industria y Sociedad (1850-1936). Como vemos el encuadre cronológico de la obra es muy claro quedando acotado desde el nacimiento y primer desarrollo de la industria aragonesa hasta el comienzo de nuestra Guerra Civil. El gran interés de este trabajo es el triple enfoque que Jiménez Zorzo aplica a la disciplina: el geográfico, con la consiguiente distribución de los restos industriales en el espacio en consonancia con la evolución de las ciudades, del urbanismo y la vertebración del territorio; el de la clasificación de sectores o grupos productivos, que analiza los diferentes sectores industriales - alimentación, energía o textil, por citar algunos ejemplos - su evolución en función de la sociedad que los demandaba y las tipologías de edificaciones que los albergaban; por último, el enfoque social que analiza desde el comportamiento de la industria en el escenario comercial (catálogos, tarjetas, exposiciones) hasta la expresión de la industria fuera del ámbito del comercio, centrándose en las artes plásticas y manifestaciones literarias.

Además de todo ello, Jiménez Zorzo ha desarrollado un importante estudio especializado en la Fundición Averly de Zaragoza - en su ubicación actual, Paseo María Agustín 59, desde 1879. A la tesina publicada en el año 1985 con el título Arqueología industrial en Zaragoza: la fábrica de fundición Averly le siguió su obra La industrialización en Aragón. La fundición Averly de Zaragoza, publicada en 1987. Ambas recogen la necesidad de un estudio de la fundición Averly además de poner en valor la introducción de la tecnología del vapor y la electricidad en la capital aragonesa. El autor analiza la fundición desde diversos ámbitos: la estructura fabril, el amplio catálogo de productos o su contribución al arte y publicidad. Estas instalaciones industriales han representado en los últi- 
mos años un importante debate entre las asociaciones ciudadanas ${ }^{18}$ en defensa del patrimonio, los entes públicos y los intereses de los colectivos privados. Afortunadamente en la actualidad este edificio industrial disfruta de protección jurídica en el nivel de bien catalogado. ${ }^{19}$

Otros autores han repasado la historia de la industrialización en Aragón desde la óptica de la necesaria recuperación del Patrimonio industrial. Entre ellos podemos citar a José Manuel Pétriz Borau y Javier Domínguez Hernández con su Arqueología industrial en la provincia de Zaragoza publicada en el año 2000. En esta obra se plantea la tardía toma de conciencia por parte de las instituciones encargadas de proteger el paisaje industrial, efectuando un repaso de la historia y estado actual de diferentes vestigios agrupados por sectores industriales (azucareras, alcoholeras, mercados, transporte, entre otros). Igualmente, José Laborda Yneva publicó en ese mismo año, junto a Biel Ibáñez y Jiménez Zorzo, su Arqueología industrial en Aragón. En él se aborda la evolución de la arquitectura industrial (recintos fabriles, naves) en relación con los procesos industriales que, paulatinamente, iban teniendo lugar en Aragón.

En cuanto a los vestigios procedentes de vías de comunicación, Santiago Parra de Mas trabajó sobre una de las líneas férreas más significativas de Aragón, el ferrocarril Zaragoza- Canfranc, ${ }^{20}$ efectuando un profundo estudio sobre la génesis del proyecto, su evolución y los acuerdos y convenios para su explotación. Parra de Mas presidió el Sindicato de iniciativa y propaganda de Aragón (SIPA) ${ }^{21}$ entre los años 1973 y 2007. El SIPA es una asociación privada fundada en el año 1925 con el objetivo de poner en valor el patrimonio, la cultura y la identidad aragonesa. Su funcionamiento ha sido ininterrumpido y su publicación Aragón Turístico y Monumental ronda las 400 entregas.

18 Entre ellas destaca la Asociación pública para la defensa del patrimonio aragonés (APUDEPA).

19 Consúltese el Boletín oficial de Aragón (BOA) de 4-9-2013, núm. 174.

20 Santiago Parra de Mas, «El ferrocarril Zaragoza-Canfranc» en María Ángeles Magallón Botaya (coord.), Caminos y comunicaciones en Aragón, Zaragoza, 1999, pp. 367-386.

21 Para ampliar la información acerca de esta asociación, sus actividades y sus publicaciones es posible visitar su oficina en Zaragoza, dentro del Colegio de Arquitectos, calle San Voto 7. 


\section{Los PRimeros PASOS EN LA GeSTIÓN DEL PATRIMONIO CULTURAL DE ARAgón}

Veamos ahora cuales fueron los primeros trabajos desarrollados en torno al Patrimonio cultural aragonés. La labor inicial consistió en la creación de un inventario, lo más extenso y detallado, posible de los restos patrimoniales que sirviera como herramienta básica para iniciar cualquier estudio posterior.

Por supuesto, todo ello ha debido contar con el abrigo de una normativa - tanto estatal como autonómica - necesaria para que las administraciones públicas puedan actuar sobre los elementos del patrimonio cultural.

\subsection{El marco jurídico. La necesaria definición del patrimonio cultural}

Las acciones a llevar a cabo sobre el patrimonio cultural de un lugar y, más concretamente, del Patrimonio industrial como parte de aquel, deben gozar de una regulación jurídica que lo defina, estudie, proteja y determine las líneas de actuación que deben ejecutarse en cada uno de los casos. En Aragón, además de las normas estatales (entre las que se destaca la Constitución Española con sus artículos 44, 46 y 149.2 y la Ley 16/1985, de 25 de junio, del Patrimonio Histórico Español), la normativa de referencia es la Ley 3/1999, de 10 marzo, ley de Patrimonio Cultural Aragonés (LPCA), ${ }^{22}$ en la que queda definido en su artículo 2 el Patrimonio Cultural Aragonés

El Patrimonio Cultural Aragonés está integrado por todos los bienes materiales e inmateriales relacionados con la historia y la cultura de Aragón que presenten interés antropológico, antrópico, histórico, artístico, arquitectónico, mobiliario, arqueológico, paleontológico, etnológico, científico, lingüístico, documental, cinematográfico, bibliográfico o técnico, hayan sido o no descubiertos y tanto si se encuentran en la superficie como en el subsuelo o bajo la superficie de las aguas. ${ }^{23}$

En la definición no aparecen referencias explicitas sobre el interés del pasado industrial o el valor tecnológico que pudiera poseer un vestigio, aunque sí se incluye la característica de «científico». Seguidamente, la nor-

22 Ley 3/1999, de 10 marzo, ley de Patrimonio Cultural Aragonés <https://www.boe.es/buscar/ pdf/1999/BOE-A-1999-8270-consolidado.pdf> [Consulta: 02-07-2019]

23 Ley 3/1999 de 10 de marzo del Patrimonio cultural aragonés, título preliminar, artículo 2. $<$ https://www.boe.es/buscar/pdf/1999/BOE-A-1999-8270-consolidado.pdf> [Consulta: 1608-2019] 
ma autonómica establece las diferentes categorías de protección para los bienes que integran el patrimonio aragonés (Título I, Capítulo I), pudiendo ser Bienes de interés cultural, bienes catalogados o bienes inventariados. En los siguientes capítulos (Capitulo II, III y IV respectivamente) el texto desarrolla de manera individual cada una de estos tres niveles.

Finalmente, debemos indicar también que los gobiernos municipales pueden desarrollar sus propios catálogos de vestigios culturales con niveles de protección local, como puede ser el de Monumento de Interés Local, descrito en el artículo 25 de la Ley 3/1999, de 10 marzo. Igualmente, esta norma vincula y obliga a los ayuntamientos a diseñar planes especiales de urbanismo con la finalidad de preservar las zonas protegidas. Es el caso de los conjuntos de interés cultural (Sección II de los Bienes de Interés Cultural) cuyas disposiciones quedan descritas en los artículos 41 y siguientes.

Una vez establecidas las bases legales que permiten el tratamiento de los vestigios culturales pasemos a analizar cuáles fueron las primeras tareas que se desarrollaron en Aragón dentro de esta novedosa disciplina.

\subsection{El imprescindible inventariado inicial. La construcción del Sistema de información del patrimonio cultural aragonés (SIPCA)}

El primer paso que se dio en el tratamiento del patrimonio cultural aragonés fue el de realizar un registro lo más extenso y detallado posible de todos los restos disponibles. Esta tarea ha sido desarrollada durante años por un equipo de investigación concienciado con la necesidad de la protección de este patrimonio, bajo coordinación del Gobierno de Aragón.

Podemos definir el inventario de los restos industriales como el registro administrativo en el que son integrados con la finalidad de abordar su clasificación, estudio, difusión y, en su caso, informar sobre la necesidad de su protección, así como proponer diferentes posibilidades de recuperación o reutilización.

Como sabemos el destino de los restos industriales es diverso. Desde su simple destrucción y desaparición total hasta la concesión de la mayor categorización de protección. En el caso de su conservación, algunas instalaciones industriales mantienen su uso original - por ejemplo, el Mercado Central o de Lanuza, en Zaragoza - aunque lo más frecuente es que se dé una utilización diferente que puede ser igualmente variada, siendo frecuentes la adaptación para usos sociales y cívicos, así como la musealiza- 
ción de las instalaciones. El valor turístico de los restos industriales también ha crecido con fuerza en los últimos años. ${ }^{24}$

Pero todo lo anterior no podría llevarse a cabo sin una correcta clasificación, catalogación y descripción de los restos patrimoniales en un registro adecuado. La inclusión de los vestigios en un registro administrativo facilitará las labores posteriores, así como servirá de soporte que difunda su existencia. Además de todo ello, un inventario organizado y eficaz es la herramienta elemental necesaria para iniciar cualquier estudio sobre los restos arqueológicos. ${ }^{25}$

La andadura del inventario de vestigios industriales en nuestro país comenzó en los años 1980 con la redacción del Catálogo Monumental de España, el Inventario Artístico y el Inventario del Patrimonio Arquitectónico, todas ellas iniciativas promovidas por el gobierno estatal. Sin embargo, estas acciones se centraron en el patrimonio histórico y artístico, especialmente en la arquitectura, teniendo poca presencia los inmuebles industriales y de obra pública.

En España, todas las comunidades autónomas en el marco de sus competencias han desarrollado su labor de inventariado. La pionera fue la Comunidad Autónoma del País Vasco que comenzó sus trabajos de registro del patrimonio en la década de 1990. En esta década las trasferencias de competencias a las comunidades autónomas hicieron que el gobierno de Aragón se encargara de las tareas de inventariado. De esta manera, a finales de los 90, la situación comenzó a cambiar en Aragón gracias a la preocupación creciente por el conocimiento del patrimonio aragonés. En 1999 la Conferencia de Empresarios de Zaragoza propuso la realización de un catálogo del patrimonio industrial de la provincia. Este proyecto fue financiado por la Diputación Provincial de Zaragoza y como resultado se diseñó un inventario de los bienes industriales de las comarcas de las Cinco Villas, Valdejalón y parte de Calatayud. Con posterioridad, el proyecto se amplió al resto de Aragón dada las visibles carencias que existían en cuanto al registro de los restos industriales en la práctica totalidad de la región.

24 Manuel Antonio Zárate Martín y María Teresa Rubio Benito, Paisaje, sociedad y cultura en geografia humana, Madrid, Ramón Areces, 2011, p. 374.

25 Sobre la gestión del Patrimonio Cultural existe una importante obra dividida en diferentes capítulos que abarcan cuestiones fundamentales como la de definir el patrimonio cultural, los mecanismos de gestión (conocimiento, planificación, protección y difusión), la legislación existentes y relación entre el patrimonio e instituciones entre otros aspectos. Véase María Ángeles Querol Fernández, Manual de gestión del Patrimonio Cultural, Madrid, Akal, 2012. 
De esta manera comenzó a gestarse en el año 2004 el catálogo del patrimonio industrial y la obra pública en Aragón..$^{26} \mathrm{El}$ proyecto contempló dos fases. La primera trató de reunir toda la documentación existente sobre el Patrimonio industrial y la obra pública aragonesa enmarcada en un límite cronológico claro: los siglos xix y xx, finalizando en los años 1970. El trabajo estableció una primera división de los vestigios:

- Arquitectura hidráulica

- Arquitectura industrial

- Obra pública

- Patrimonio tecnológico

- Patrimonio documental

El extensísimo material objeto del estudio produjo una de las primeras consecuencias de este proyecto: la generación de un importante grupo universitario de trabajo compuesto por investigadores y tres coordinadores - uno por provincia - todos ellos relacionados con la Historia del Arte. ${ }^{27}$

El modo de trabajo llevado a cabo consistió en el registro y análisis sistemáticos de los restos industriales y de obra pública por comarcas, siendo una de las primeras la de Andorra-Sierra Los Arcos. Los investigadores de este grupo siempre han cuidado mucho el aspecto geográfico del estudio con la intención de mantener en todo momento la ligazón del vestigio industrial a su entorno geográfico ${ }^{28}$. Para ello, la interdisciplinaridad ha sido fundamental, habiendo contado con la ayuda del personal del departamento de Sistemas de Información Avanzados del Centro Politécnico Superior de la Universidad de Zaragoza, en lo referente a localización GPS, ortofotos, sistemas de información geográfica (SIG) así como en el tratamiento de los datos.

26 María Pilar Biel Ibáñez, 2007, pp. 255-274.

27 El grupo de trabajo inicial fue compuesto por Pilar Biel Ibáñez, Asunción Urgel Masip, Javier Jiménez Zorzo, María García Soria, Miguel Ángel Cebrián, María Pilar García, Natalia Juan García, Jorge Arruga, María Vecino, Carolina Chávez, Francisco Lázaro Sebastián, Jacobo Henar Barriga, Iban Andrea y Paula García.

28 La gran importancia del estudio, protección y actuación sobre un vestigio industrial en su ubicación original ha sido defendida por numerosos autores. Véase, por ejemplo, María Pilar Biel Ibáñez, «¿Conservamos o adaptamos el patrimonio?», Artigrama, 11, 1994-95, pp. 495-500. 
El material obtenido (descripción, análisis, fotografías, localización) fue introducido en el Sistema de Información del Patrimonio Cultural Aragonés (SIPCA). ${ }^{29}$ Este elemento es una potente base de datos informática proporcionada por el gobierno autonómico con la intención de que constituya la herramienta principal para el inicio de cualquier estudio sobre Patrimonio industrial aragonés. Además de todo ello, el SIPCA es un registro dinámico ya que fueron incorporándose paulatinamente los inventarios de patrimonio artístico o histórico, así como etnográfico y arqueológico. Actualmente el SIPCA integra, además de lo anterior, entradas a contenidos sobre patrimonio lingüístico de Aragón, tradición oral y musical y a una red de museos a nivel autonómico y estatal.

Finalmente, la última etapa del trabajo en esta primera fase del proyecto consistió en la emisión de informes por parte de los expertos, una vez analizados todos los datos, que plantearan las necesidades de proteger el resto industrial y las posibilidades que ofrece de cara a su futuro.

La segunda fase de trabajo del catálogo de patrimonio industrial y obra pública en Aragón se basó en la investigación en archivos y hemerotecas en relación a los bienes estudiados. Esta fase es igualmente indispensable para poder alcanzar un conocimiento de los restos inventariados además de poder trasladar el estudio a otros ámbitos como el histórico-social de la época que generó los restos industriales. Se pueden obtener datos de los modelos productivos, las implementaciones de maquinaria y tecnología, así como las rutinas y costumbres de las gentes del lugar donde se integró el elemento industrial o de obra pública. En el SIPCA se incluye actualmente un subapartado destinado a los documentos y archivos de Aragón (DARA).

\subsection{Los resultados: las fichas del SIPCA}

Una vez desarrolladas las tareas de inventariado es importante presentar los resultados de una manera clara, completa y con un buen soporte documental. Estas arduas tareas se vieron cristalizadas en las fichas del SIPCA que actualmente conforman un banco de datos de más de 15000 entradas. El sistema SIPCA constituye un elemento fundamental para la aproximación e inicio de cualquier estudio de arqueología industrial en Aragón.

29 El SIPCA puede ser consultado en el siguiente enlace: $<$ http://www.sipca.es/>. 
El buscador SIPCA permite hacer una búsqueda sencilla - simplemente indicando el nombre o denominación básica del bien a buscar- o una búsqueda avanzada bajo criterios establecidos en cuatro campos:

- Datos generales: nombre, clasificación y tipo de bien

- Localización del bien: provincia, comarca, municipio y localidad

- Protección jurídica: clase, categoría y figura

- Historia: Datación (exacta o intervalo de fechas), estilo y personas relacionadas.

La presentación de los resultados se efectúa mediante una ficha en la que aparece distinta información del vestigio como su denominación e identificación, su localización o su evolución histórica (creación, uso principal y fin de utilización). También encontramos enlazados otros datos de interés, como pueden ser las resoluciones normativas que otorgan protección a los restos, si es que gozan de ella.

En la mayoría de los casos el aporte visual existe. Sin embargo, en los restos menos analizados es escaso, presentando una sola imagen actual. En cambio, en otras fichas podemos consultar múltiples imágenes actuales y de la época pasada, cuando el edificio industrial se dedicaba a su labor originaria.

La inclusión de fuentes a las que puede acudirse para ampliar la información del resto estudiado es también un aspecto positivo de la ficha del SIPCA. Igualmente, tal y como se ha comentado, la conservación de la ligadura entre el bien industrial y su entorno geográfico ha sido muy cuidado por los investigadores que confeccionaron el inventario. En estas fichas puede verse su localización exacta mediante coordenadas geográficas que, además, son descargables digitalmente. Es un buen ejemplo del uso de las herramientas informáticas y geográficas al servicio de la arqueología industrial.

Por último, la difusión de los datos y la posibilidad de descargarlos - en formato pdf - por parte de los usuarios del SIPCA convierte realmente a esta base de datos en una herramienta fundamental para cualquier investigador o estudioso que desee acercarse a los restos industriales.

\section{LA IMPORTANCIA DEL SECTOR ENERGÉTICO ARAGONÉS. INICIOS Y EVOLUCIÓN}

El proceso de industrialización alcanzó a España en las últimas décadas del siglo xix coincidiendo con la consolidación del Estado liberal, es decir, 


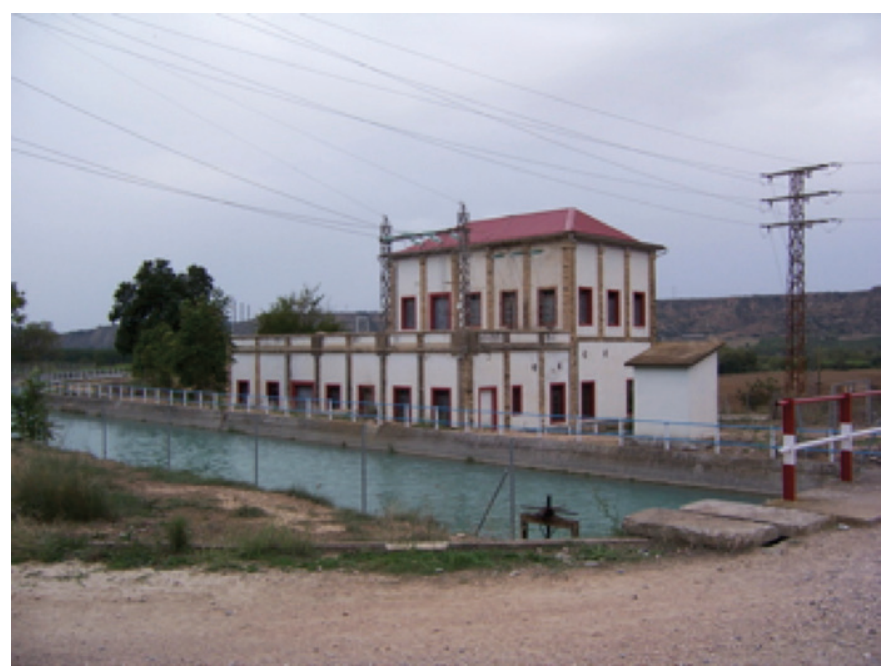

Imagen 1. Central eléctrica de Estadilla (Huesca). Fuente: SIPCA

con un visible retardo con respecto a otras naciones europeas, como Francia o Alemania, que recibieron más tempranamente las innovaciones tecnológicas provenientes de Inglaterra, cuna de la Revolución Industrial. Además, en el interior de España también pueden apreciarse diferencias entre territorios, regiones o comunidades autónomas. En este sentido Aragón, donde la industrialización fue un proceso largo y discontinuo con fases de estancamientos y de leves aceleraciones, ${ }^{30}$ accedió con cierto retraso a la innovación tecnológica e industrialización con respecto a comunidades autónomas como, por ejemplo, Cataluña o País Vasco.

Dentro de este contexto, el sector de la generación energética se constituyó como un elemento fundamental para el avance productivo y tecnológico de cualquier territorio. Junto a todo ello, el negocio de la energía motivó la atracción de capital foráneo y contribuyó en gran medida a articular una red financiera en las principales capitales, como es el caso de Zaragoza y la confluencia de fondos vascos, catalanes o madrileños. En Aragón se puede considerar que la explotación de la electricidad comenzó en el año 1893, con la constitución de las sociedades zaragozanas Electro

30 José Antonio Biescas Ferrer, Introducción a la economía de la región aragonesa, Zaragoza, Alcrudo, 1977, p. 171. 
Peral y Compañía Aragonesa de Electricidad. La producción energética aragonesa ha estado fundamentada principalmente en dos modelos: por un lado, el relacionado con los aprovechamientos hidráulicos, correspondiente a las primeras explotaciones, y por otro lado el ligado a la explotación minera, que aumentó su presencia con posterioridad. A finales del siglo xix y principios del xx, la elección de uno de estos dos modelos de producción eléctrica no estuvo exenta de debate y polémica entre defensores de una y otra tecnología, decantándose finalmente por el modelo hidroeléctrico. ${ }^{31}$

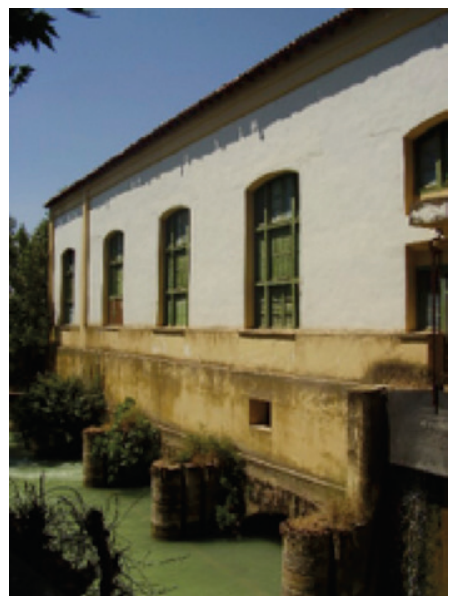

Imagen 2. Central hidroeléctrica de Marracos (Zaragoza). Fuente: SIPCA

\subsection{La hidroelectricidad}

Comencemos por el sector de generación energética ligada a la red natural hidráulica. Si bien únicamente la mitad de las diez centrales eléctricas aragonesas con una potencia superior a los $25 \mathrm{~kW}$ construidas entre 1893 y 1896 utilizó la energía hidráulica - la otra mitad empleó vapor de agua y gas-, la construcción de centrales a finales del xix estuvo muy ligada a los aprovechamientos hidráulicos. ${ }^{32}$ De esta manera la hidroelectricidad obtuvo un gran peso específico en la producción energética en Aragón a principios del siglo $\mathrm{xx}$ mientras que el resto de España siguió basando su generación energética

31 Francisco Javier Jiménez Zorzo, tesina Arqueología industrial en Zaragoza: la fábrica de fundición Averly, Universidad de Zaragoza, 1985, p. 38.

32 Luis Germán Zubero, «El desarrollo de la industria eléctrica en Aragón (1893-1935)» en Atlas de Historia de Aragón, núm. 94, Zaragoza, IFC, 1991. 
en el vapor de agua a presión. Entre los años 1901 y 1904 la producción energética aragonesa representaba el $4 \%$ de la total nacional, ${ }^{33}$ destacando en el panorama energético regional las dos sociedades mencionadas con sus dos centrales generadoras: Electro Peral y la Compañía Aragonesa de Electricidad. A ellas debe añadirse la central de Estadilla (Huesca) perteneciente a Eléctricas del Cinca. Ninguna de ellas superó los $1000 \mathrm{~kW}$ de potencia.

Posteriormente se crearon dos centrales que lideraron el sector hidroeléctrico hasta 1918. Una de ellas es la central de Marracos (Zaragoza), inaugurada en 1904 y perteneciente a Fuerzas Motrices del Gállego. La otra es la central de Carcavilla (Huesca) propiedad de la Sociedad Teledinámica del Gállego. ${ }^{34}$ Ambas centrales eran muy similares en potencia, superando los $4000 \mathrm{~kW}$. En la actualidad, estas plantas energéticas continúan operativas tras las reformas necesarias para mejorar sus rendimientos.

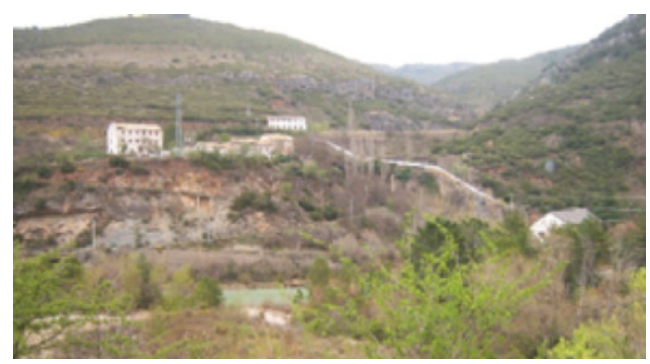

Imagen 3. Central hidroeléctrica de Carcavilla (Huesca) y su entorno natural. Fuente: SIPCA

En los años posteriores fue organizándose la constitución de la sociedad Eléctricas Reunidas de Zaragoza (ERZ) que culminó en el año $1911 .{ }^{35}$ Esta entidad adquirió un protagonismo casi pleno dentro del sector energético zaragozano hasta la Guerra Civil. No obstante, aparecieron pequeñas centrales eléctricas con objetivos modestos consistentes en el suministro eléctrico local o, en el mayor de los casos, comarcal. Tras la Guerra Civil fueron pasando a manos de ERZ generalmente bajo la condición de filiales. Dentro de estas pequeñas instalaciones podemos citar la empresa Molino Harinero y Luz Eléctrica de Jaca, en la comarca de la Jacetania. En Tardienta encon-

33 Germán Zubero, 1991, núm. 94.

34 Biescas Ferrer, 1977, p. 187.

35 Eléctricas Reunidas de Zaragoza comienza a gestarse en 1904 bajo la unión de la Compañía Aragonesa de Electricidad, Electra Peral Zaragozana y Fuerzas Motrices del Gállego con el objetivo de la explotación conjunta del negocio de la electricidad en Zaragoza. 
tramos la sociedad Electra de Tardienta. En cuanto a la provincia de Zaragoza, podemos incluir las compañías Electra Jalón y la Industrial Jalonesa y Saltos del Huerva y del Jalón, con centrales en el cauce del río Jalón. En Teruel aparece una empresa del lugar pero con la central eléctrica fuera de la comunidad. Se trata de Electra Sierra Menera que distribuyó energía a trece municipios turolenses colindantes con Guadalajara, provincia en la que se ubicaba su central (en concreto, en la localidad de Checa).

El periodo de entreguerras fue de notable expansión debido al aprovechamiento de los recursos hídricos pirenaicos y del río Ebro con capital vasco, madrileño o catalán. Como vemos se trata de regiones con un importante nivel de industrialización y, por tanto, con unas elevadas necesidades energéticas. Ante esta situación, el desarrollo hidroeléctrico de la comarca del Alto Aragón fue espectacular aupando a la provincia de Huesca como la segunda, tras la vecina Lérida con condiciones muy parecidas, en la clasificación de producción energética nacional anterior a la contienda civil. De esta manera Aragón adquirió un notable protagonismo en la capacidad productiva energética nacional pasando de representar un 4,7\% a principios de los años 20 a un $12,8 \%$ en 1935 . En ese año la producción eléctrica aragonesa representaba un $17 \%$ del total nacional ${ }^{36}$.

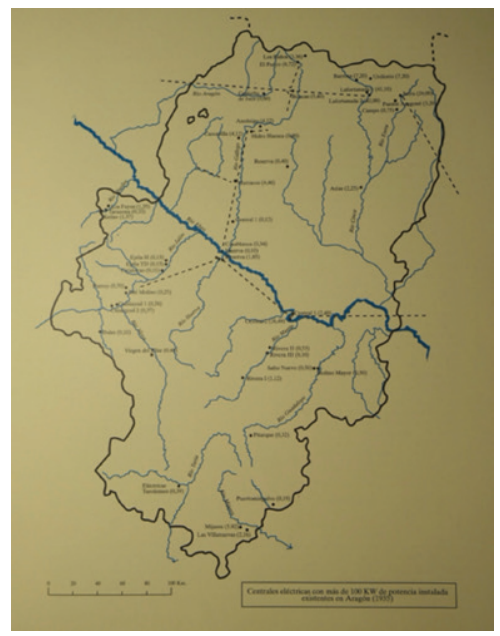

Mapa 1. Centrales eléctricas de más de $100 \mathrm{KW}$ de potencia instalada en Aragón (1935).

Fuente: Atlas de Historia de Aragón (1991), n. ${ }^{\circ} 94$.

36 Luis Germán Zubero, Historia económica del Aragón contemporáneo, Zaragoza, PUZ, 2012, p. 246. 
En el mapa anterior puede verse la implantación de centrales generadoras de más de $100 \mathrm{kWatios}$ de potencia instalada en el año 1935. Es claro el aprovechamiento hidráulico de los ríos y, por ese motivo, la amplia instalación de estas plantas en el sector altopirenaico.

En cuanto a la evolución de la potencia eléctrica instalada en Aragón comparada con el total español es posible sintetizar a continuación algunos datos significativos:

Tabla I. Evolución de la industria eléctrica en Aragón (1900-1935) en potencia instalada (miles de kW)

\begin{tabular}{|l|c|c|c|c|}
\hline & $\mathbf{1 9 0 1}$ & $\mathbf{1 9 0 4}$ & $\mathbf{1 9 2 1}$ & $\mathbf{1 9 3 5}$ \\
\hline Huesca & 0.2 & 0.4 & 28.2 & 148.3 \\
\hline Teruel & 0.4 & 0.7 & 4.5 & 11.6 \\
\hline Zaragoza & 2.4 & 3.0 & 10.9 & 35.4 \\
\hline Aragón & 3.0 & 4.2 & 43.6 & 195.4 \\
\hline \% total España & 3.8 & 4.2 & 4.7 & 13.2 \\
\hline
\end{tabular}

Fuente: Luis Germán Zubero, 2012: 245.

En la tabla se observa fácilmente el incremento de la industria eléctrica de Aragón. Tal y como se ha indicado, debe hacerse una especial mención a la provincia de Huesca, donde el crecimiento fue enorme debido a la explotación de la red hidráulica pirenaica.

Algunas empresas ligadas al sector que trabajaron en Aragón fueron la sociedad Hidroeléctrica Ibérica, de origen vasco, con aprovechamientos en el Cinca y el Cinqueta: se canalizó así la energía producida hacia el sector bilbaíno. Por su parte, Catalana de Gas y Electricidad inició su actividad en 1918 en las aguas del rio Ésera, trasportando la producción hacia Barcelona. Igualmente catalana, la empresa Electro Metalúrgica del Ebro (EMESA) acondicionó sus instalaciones en aguas del Ebro a su paso por Sástago. Suministró electricidad a ERZ desde finales de los años veinte. Por último, citemos a la sociedad Energías e Industrias Aragonesas (EIASA), fundada en Barcelona en 1918 y vinculada al Banco Urquijo, ${ }^{37}$

37 El grupo Urquijo fue uno de las agrupaciones financieras no aragonesas presentes en Aragón en el panorama económico del periodo de entreguerras. Su capital, de origen madrileño, junto con el vasco y catalán, contribuyó a articular la red financiera zaragoza. El origen del Banco Urquijo se remonta a 1870 en Madrid. 
con aprovechamientos de sus instalaciones en el río Gállego que derivaba la energía a las electroquímicas de Sabiñánigo. ${ }^{38}$

\subsection{La producción térmica}

Tras analizar el sector productor energético basado en el potencial hidráulico, pasemos a presentar la segunda de las modalidades de producción energética mayoritaria en Aragón: la producción térmica. Este tipo de generación se basa en la producción de vapor de agua mediante la combustión de elementos fósiles como petróleo, carbón o gas. Por ello la termoelectricidad ha estado íntimamente ligada a las actividades extractivas y, por tanto, a aquellos lugares que ofrecieron mejores posibilidades. Uno de los casos más significativos en Aragón es el de las comarcas turolenses de las Cuencas Mineras y Andorra, donde minería y producción térmica han estado inevitablemente unidas. Como ejemplos pueden citarse las centrales de Aliaga (cerrada en el año 1982) y la de Teruel, ${ }^{39}$ en Andorra.

Tabla II. Cuota eléctrica (\% en el total español) de Aragón entre 1975 y 2000 dividido en los subsectores hidroeléctrico y térmico

\begin{tabular}{|c|c|c|c|c|c|c|c|}
\hline & $\begin{array}{c}\text { PotenCIA } \\
\text { INSTALADA }\end{array}$ & $\begin{array}{c}\text { ProducCión } \\
\text { ELÉCTRICA }\end{array}$ & & & & & \\
\hline & MW & HidR. & TÉRM. & TOTAL & HIDR. & TÉRM. & TOTAL \\
\hline $\mathbf{1 9 7 5}$ & 1600 & 9,9 & 3,1 & 6,3 & 13,8 & 4,0 & 7,1 \\
\hline $\mathbf{1 9 8 0}$ & 2564 & 8,9 & 7,7 & 8,2 & 10,5 & 8,6 & 9,1 \\
\hline $\mathbf{1 9 8 5}$ & 2740 & 9,8 & 4,9 & 6,6 & 10,0 & 8,8 & 9,1 \\
\hline $\mathbf{1 9 9 0}$ & 2817 & 8,8 & 4,7 & 6,2 & 9,3 & 5,9 & 6,5 \\
\hline $\mathbf{1 9 9 5}$ & 2969 & 8,5 & 4,8 & 6,1 & 11,2 & 6,8 & 7,4 \\
\hline $\mathbf{2 0 0 0}$ & 3175 & 8,3 & 5,0 & 6,1 & 10,0 & 5,7 & 6,3 \\
\hline
\end{tabular}

Fuente: Luis Germán Zubero, 2012: 377

38 Germán Zubero, 2012, pp. 245-246.

39 La denominación formal de esta planta es «central térmica de Teruel», tal y como puede verse en el catálogo de instalaciones de la empresa propietaria, ENDESA: <https://www.endesa. com/es/mapa-centrales.html> No obstante, es muy frecuente referirse a ella como «central térmica de Andorra», dado que está situada en esa localidad turolense. En el presente trabajo se ha optado por utilizar la nomenclatura formal. 
A pesar del gran protagonismo de la generación hidráulica en Aragón, la térmica aumentó considerablemente su presencia en el último cuarto del siglo xx, pasando de un 38\% de cuota de generación en 1975 a un $76 \%$ en el año $2000 .{ }^{40}$ Este salto cuantitativo estuvo muy relacionado con la puesta en marcha en el año 1979 - en plena etapa de crisis petrolífera - de la central térmica de Teruel (Andorra), con una potencia instalada de 1050MW.

Como puede observarse en la tabla, la potencia instalada hidroeléctrica y su producción presentan una evolución estable a lo largo del último cuarto del siglo xx.

Sin embargo, en el subsector térmico se contemplan ciertas variaciones. En primer lugar, la potencia instalada y la producción experimentan un gran salto en el lustro entre 1975 y 1980 sin duda debido a la activación de la central de Teruel (Andorra). En segundo lugar, puede verse en el siguiente periodo, de 1980 a 1985, que la potencia instalada decrece a pesar de mantener constante la producción térmica. Uno de los motivos es el cierre de la central térmica de Aliaga en 1982. El hecho de que la productividad eléctrica permanezca constante en ese lapso, indica que los últimos años de uso de esta planta la potencia suministrada fue mínima. En tercer y último lugar, a partir de la década de los 90 del pasado siglo, la producción eléctrica térmica disminuye en clara relación con un mayor uso de energías alternativas menos contaminantes. En ese momento la potencia instalada permanece constante todavía, a la espera de su disminución, provocado por los cierres de plantas productoras, como la de Escucha (en 2013) a la que se sumará en un futuro muy cercano (previsiblemente en el segundo semestre de 2020) la de Teruel (Andorra), cuya potencia eléctrica es considerable (actualmente 1101MW). ${ }^{41}$

Por último, tal y como se ha indicado, encontramos una relación directa entre producción de energía térmica y extracción de mineral combustible. En la etapa de crisis petrolífera (1975-1985) la generación termoeléctrica se basó en la producción de lignitos, entre ellos el lignito negro de Aragón. Sin embargo, esta producción de mineral descendió paulatinamente a favor de unas importaciones cada vez mayores que poco a poco fueron empeorando las perspectivas de futuro de las explotaciones mineras en nuestra comunidad. Se impusieron las explotaciones a cielo abierto con una reducción acusada de las plantillas de trabajadores.

40 Germán Zubero, 2012, p. 377.

41 Según datos proporcionados por ENDESA, aunque la actualización de los mismos es de diciembre de 2017. <https://www.endesa.com/es/mapa-centrales.html> [Consulta: 31-12-2019] 


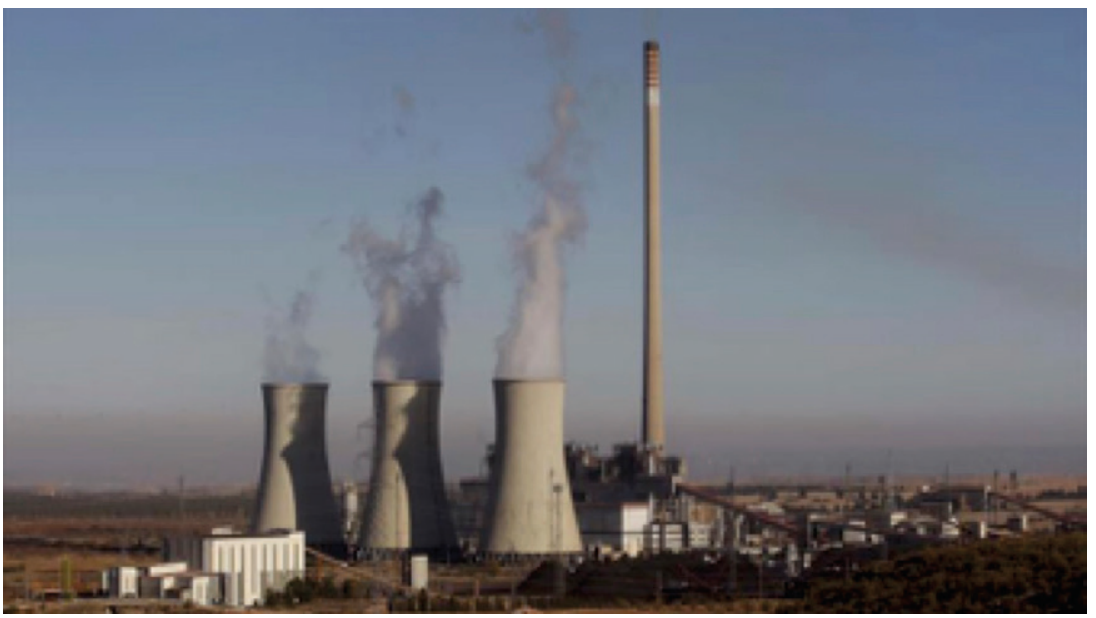

Imagen 4. Central térmica de Andorra (Teruel) en la actualidad.

Fuente: El Periódico de Aragón, 23/02/2018 (https://www.elperiodicodearagon.com)

En la siguiente tabla podemos observar la evolución de la producción de lignitos en Aragón en comparación con la producción carbonífera total española y el volumen de importación:

Tabla III. Evolución de la producción de lignitos en Aragón entre 1975 y 2000 (miles de tm)

\begin{tabular}{|l|c|c|c|c|c|c|}
\hline & $\begin{array}{c}\text { PRODUCCIÓN } \\
\text { DE LIGNITOS }\end{array}$ & $\begin{array}{c}\text { TOTAL } \\
\text { CARBÓN }\end{array}$ & $\begin{array}{c}\text { IMPORTACIÓN } \\
\text { (HULLA) }\end{array}$ & & & \\
\hline & TERUEL & ESPAÑA & \% TERUEL & ESPAÑA & \% TERUEL & \\
\hline $\mathbf{1 9 7 5}$ & 2127 & 3380 & 62,9 & 14003 & 15,2 & \\
\hline $\mathbf{1 9 8 0}$ & 3233 & 15459 & 20,9 & 28687 & 11,3 & $2782^{2}$ \\
\hline $\mathbf{1 9 8 5}$ & 5117 & 23570 & 21,7 & 39754 & 12,9 & 4297 \\
\hline $\mathbf{1 9 9 0}$ & 34111 & 20951 & 16,3 & 35897 & 9,5 & 6286 \\
\hline $\mathbf{1 9 9 5}$ & 3525 & 14812 & 23,8 & 28411 & 12,4 & 10595 \\
\hline $\mathbf{2 0 0 0}$ & 3105 & 12152 & 25,6 & 23486 & 13,2 & 17225 \\
\hline
\end{tabular}

Fuente: Luis Germán Zubero, 2012: 379. ${ }^{1}$ dato para el año 1991. ${ }^{2}$ dato para el año 1983

Como podemos observar el peso específico del lignito turolense fue muy elevado hasta 1975, año en el que se cuantificó en un 62,9 \% del total nacional. Sin embargo, el extraordinario crecimiento de la producción de 
lignito pardo en La Coruña - con destino a la térmica de Puentes de García Rodríguez (La Coruña) ${ }^{42}$ - eclipsó la presencia del mineral de Teruel pasando a representar en 1980 el 20,9 \% del total español.

Además de ello, puede observarse una tendencia bajista en la producción de lignito a nivel nacional a partir del año 1985. Si asociamos este dato con el de un paulatino aumento de la importación de hulla energética a partir de 1980 concluimos que el carbón nacional se ha ido sustituyendo en gran medida por mineral extranjero atendiendo, con toda probabilidad, a factores comerciales más beneficiosos.

En definitiva, se observa como el sector de la producción energética tuvo una importante significación en Aragón, representando una considerable cuota de potencia ofrecida dentro del panorama nacional. Este relevante sector no solo produjo energía, sino que dinamizó el territorio donde se ubicó, fijó población y constituyó una fuente de riqueza para las personas. Sin embargo, actualmente, los vestigios industriales que la producción energética dejó en Aragón carecen de un análisis, protección y reutilización dignos. Pasemos a analizar este asunto más detenidamente en los siguientes apartados.

\section{El PATRIMONIO CULTURAL INDUSTRIAL PROTEGIDO DE ArAgón. LA INVISIBILIDAD DEL SECTOR ENERGÉTICO}

Una vez estudiada la importancia que ha tenido el sector energético en Aragón pasemos a analizar la presencia que poseen sus vestigios industriales dentro de los registros que contienen el patrimonio cultural.

Tal y como se ha indicado anteriormente, las fichas SIPCA son una herramienta fundamental a la hora de comenzar un estudio relacionado con el patrimonio aragonés. En cuando a la generación de energía, el SIPCA ofrece los siguientes resultados. Dentro del apartado correspondiente a patrimonio arquitectónico este sistema cataloga más de 15000 obras de arquitectura e ingeniería dedicadas a diferentes usos presentes en las tres provincias aragonesas. Por ello la precisión en la búsqueda y filtrado de los datos es importantes.

42 Planta térmica perteneciente a ENDESA inaugurada en el año 1976 con una potencia de 1400 MW, superior a la central de Teruel. En 2008 fue ampliada con un ciclo combinado (gas) llegando su potencia actual a de $2421 \mathrm{MW}$, en una clara apuesta de la propietaria por la continuidad de esta instalación. 
Se han efectuado tres búsquedas diferentes bajo la clasificación de arquitectura industrial para comprobar los resultados que nos ofrece el sistema: ${ }^{43}$

Búsqueda 1. Filtro utilizado: «Centrales eléctricas». Resultados obtenidos: 9 entradas ( 5 en Huesca y 4 en Teruel). Este filtrado ofrece resultados de 9 instalaciones relacionadas con el aprovechamiento hidroeléctrico a pequeña escala. Alguna de ellas no se ha podido acceder, como es el caso de la central de Ésera-Cinca en El Grado, en cuya ficha indica claramente que apenas se posee información acerca de este resto salvo los pocos datos obtenidos bajo la historia oral del lugar. Por el contrario, otro vestigio encontrado en esta búsqueda sí que arroja una buena información: es el caso de la Fábrica de luz de Burbáguena (Teruel).

Búsqueda 2. Filtro utilizado: "Centrales hidroeléctricas». Resultados obtenidos: 72 entradas (27 en Huesca, 19 en Zaragoza y 26 en Teruel). La utilización de un filtro de búsqueda más selectivo ofrece unos mejores resultados. En este caso la aparición de las 72 entradas corresponde con instalaciones productoras de hidroelectricidad - perteneciendo la mayoría a la provincia de Huesca-, representando una búsqueda mucho más eficaz. Tal y como se ha comentado anteriormente, cada construcción encontrada permite el acceso a sus datos de identificación, historia y tradiciones. Se muestra igualmente un registro fotográfico del resto industrial además de su localización precisa mediante herramientas informáticas de localización (coordenadas geográficas sobre la aplicación Google Maps).

Búsqueda 3. Filtro utilizado: «Centrales térmicas». Resultados obtenidos: 4 entradas ( 3 en Teruel y 1 en Zaragoza). En esta búsqueda resulta interesante observar la inclusión en el catálogo de las construcciones productoras de electricidad - mediante combustión de carbón, principalmente- en desuso, como las de Aliaga o Escucha, pero también en activo, como es el caso de la térmica de Teruel (Andorra) o Escatrón. ${ }^{44}$

Entre ellas, la central de Aliaga destaca por su tamaño, calidad constructiva, conservación de edificios auxiliares y por la dinamización del territorio que produjo en su época de actividad (1952-1982). Lamentablemente, actualmente permanece en estado de abandono.

43 Consulta en el SIPCA realizada el 10-01-2020.

44 Pueden consultarse las fichas SIPCA de las cuatro plantas en la siguiente página web: $<\mathrm{http} / / /$ www.sipca.es/censo/resultados_busqueda_avanzada.html?tipobien=INM\&accion=BUSCAR_ BIENES\&categoria $=13 \&$ tipo $=567 \&$ tipobusqueda $=$ exacta $>$ [Consulta: $10-01-2020$ ] 


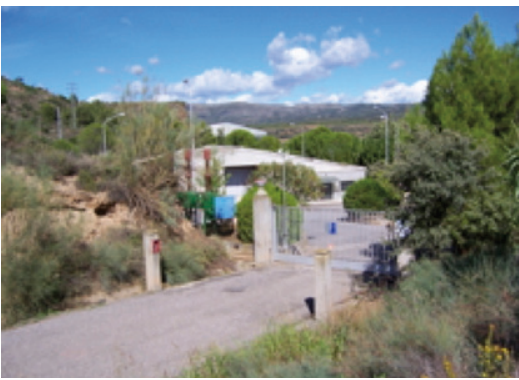

Imagen 5. Central de Ésera-Cinca, en El Grado (Huesca). Fuente: SIPCA

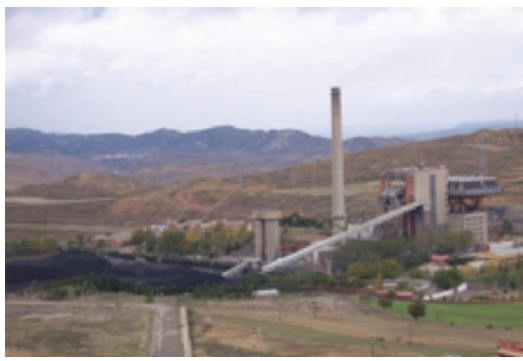

Imagen 7. Central térmica de Escucha (Teruel). Fuente: SIPCA

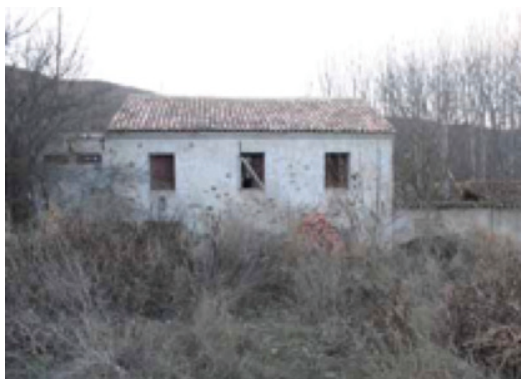

Imagen 6. Fábrica de luz de Burbáguena

(Teruel). Fuente: SIPCA

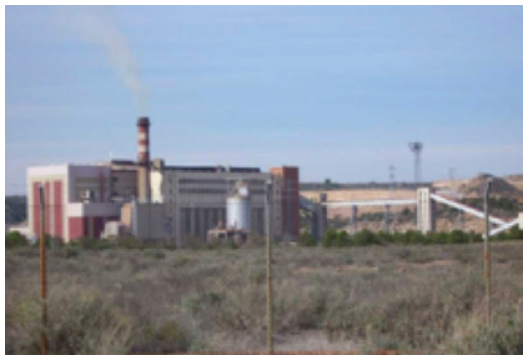

Imagen 8. Central termoeléctrica de Escatrón (Zaragoza). Fuente: SIPCA.

Entre los edificios auxiliares de esta central podemos encontrar, entre otros, la casa del director de la planta o el antiguo almacén de material. El primero posee un alto valor arquitectónico en el que se fusionan las tendencias constructivas aragonesas con las características de las viviendas obreras. Actualmente está restaurada y es utilizada como restaurante. El segundo es utilizado como centro de visitantes del Parque Geológico de Aliaga. Estos edificios secundarios forman parte también del amplio y rico patrimonio industrial relacionado con la generación energética.

Así pues, el sector de la producción de energía está presente en los inventarios de vestigios industriales. Cuantitativamente no es muy grande (85 entradas que representan apenas un $9 \%$ del total de los 817 registros dentro de la categoría de «Arquitectura industrial»); pero la tarea desarrollada en cuanto a catalogación, documentación y captación de datos históricos posee un importante valor. No obstante, el registro SIPCA incluye tanto los vestigios industriales que gozan de algún nivel de protección ju- 
rídica como los que no. Pasemos a analizar ahora únicamente aquellos restos industriales que están presentes en el catálogo de la Dirección General de Cultura y Patrimonio del Gobierno de Aragón, es decir, aquellos que disfrutan de una protección por parte de las administraciones públicas.

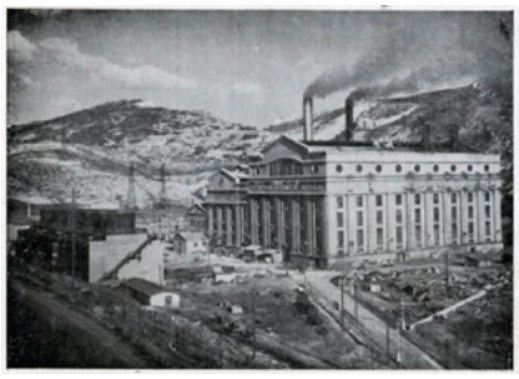

Imagen 9. Central térmica de Aliaga (Teruel). Fachada noroeste en 1955, antes de la última ampliación. Fuente: <https:// cerradoporabandono.wordpress.com/ fabricas/aliaga-la-fabrica-del-silencio/>

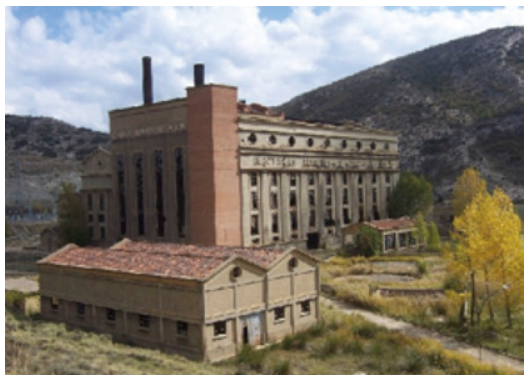

Imagen 10. Central térmica de Aliaga en la actualidad. Fuente: SIPCA

Tal y como se ha indicado, la normativa autonómica aragonesa contempla tres categorías de protección hacia los bienes y restos culturales: bien de interés cultural (BIC); bien catalogado; y bien inventariado. A pesar de que los registros del SIPCA son muy numerosos, no todos los bienes inventariados en él disponen de algún tipo de protección autonómica o local. De hecho, el SIPCA contiene más de 15000 fichas mientras que la base de datos de la Dirección General de Cultura y Patrimonio de Aragón - en la que se incluyen solamente los restos con alguna categoría de protección, bien sea estatal, autonómica o municipal - alberga únicamente 2775 fichas en la actualidad ${ }^{45}$ (enero de 2020), lo que supone aproximadamente un $18 \%$ de la totalidad de bienes registrados en el SIPCA.

La presentación de los resultados de la base de datos de la Dirección General de Cultura y Patrimonio se realiza según ocho campos de búsqueda que pueden ser escogidos libremente: provincia, comarca, municipio, tipo de bien, contexto cultural, categoría, tipología y miscelánea. La posi-

45 Número de entradas tras la consulta realizada en $<$ http://www.patrimonioculturaldearagon.es/ buscador?p_p_id=solrSearch_WAR_solrsearchportlet\&tipo=bien-cultural $>$ [Consulta: 6-1-2020] 


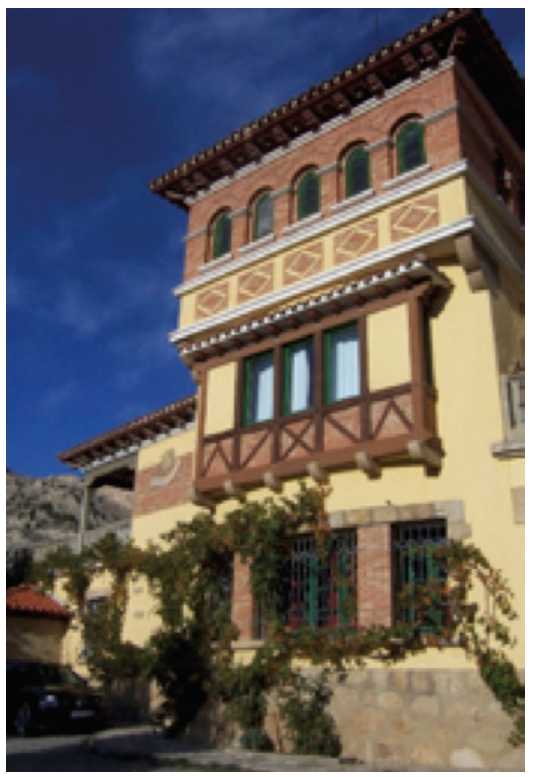

Imagen 11. Vivienda del director de la central térmica de Aliaga (Teruel). Fuente: SIPCA

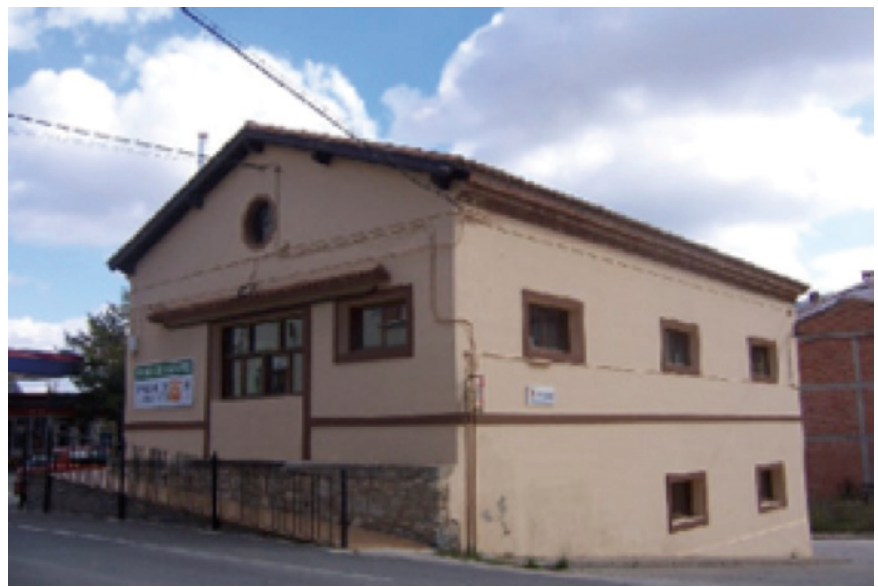

Imagen 12. Almacén de material de la central térmica de Aliaga (Teruel). Fuente: SIPCA 
bilidad de combinar todos estos campos de búsqueda ofrece unas búsquedas bastante eficaces y específicas en función de los criterios seleccionados. La información facilitada por el buscador aporta datos sobre la clasificación del bien consultado, así como su categoría de protección. La base de datos dispone de material fotográfico y de localización geográfica - aunque no es posible descargar las coordenadas geolocalizadoras.

El siguiente paso ha sido efectuar una búsqueda de los restos industriales que poseen alguna categoría de protección por parte del Gobierno autonómico o por parte de las entidades locales. Para ello se han realizado tres consultas. En primer lugar, se ha efectuado una búsqueda bajo el filtro de «arquitectura industrial» ofrecida en las opciones avanzadas de búsqueda en el buscador del Patrimonio Cultural dentro de la categoría «contexto cultural». El resultado (Tabla IV) es de ocho entradas repartidas entre la provincia de Zaragoza (5) y Teruel (3).

Tabla IV. Resultado de la búsqueda bajo el criterio de 'Arquitectura industrial' en el catálogo de la Dirección General de Cultura y Patrimonio de la DGA.

\begin{tabular}{|l|l|l|}
\hline $\begin{array}{l}\text { DENOMINACIÓN DEL BIEN } \\
\text { INDUSTRIAL }\end{array}$ & $\begin{array}{l}\text { LOCALIZACIÓN } \\
\text { (PROVINCIA) }\end{array}$ & $\begin{array}{l}\text { CATEGORÍA DE } \\
\text { PROTECCIÓN }\end{array}$ \\
\hline $\begin{array}{l}\text { Tolvas del cargadero de mineral y nave } \\
\text { de clasificación y cribado }\end{array}$ & Ojos Negros (Teruel) & $\begin{array}{l}\text { Bien catalogado } \\
\text { de interés local }\end{array}$ \\
\hline $\begin{array}{l}\text { Antiguo matadero municipal de Za- } \\
\text { ragoza }\end{array}$ & Zaragoza (Zaragoza) & Bien catalogado \\
\hline $\begin{array}{l}\text { Antigua fábrica azucarera de Nuestra } \\
\text { Señora de las Mercedes }\end{array}$ & Alagón (Zaragoza) & Bien catalogado \\
\hline Chimenea de la Resinera del Carmen & Teruel (Teruel) & Bien catalogado \\
\hline Antigua fábrica Azucarera Labradora & Calatayud (Zaragoza) & Bien catalogado \\
\hline $\begin{array}{l}\text { Nave de máquinas de la antigua esta- } \\
\text { ción de ferrocarril }\end{array}$ & Tarazona (Zaragoza) & Bien catalogado \\
\hline $\begin{array}{l}\text { Chimenea de la antigua fábrica de } \\
\text { sulfuro }\end{array}$ & Caspe (Zaragoza) & Monumento de interés \\
\hline $\begin{array}{l}\text { Instalaciones alfareras del barrio de las } \\
\text { Ollerías de San Julián }\end{array}$ & Teruel (Teruel) & Bien catalogado \\
\hline
\end{tabular}

Fuente: elaboración propia a partir de los datos del catálogo de la Dirección General de Cultura y Patrimonio.

En segundo lugar, se ha efectuado un rastreo bajo los criterios de «inmueble» dentro del campo «tipo de bien», al que se ha sumado el criterio de «industrial» en el campo «categoría» siendo el resultado de 14 entradas -2 en Huesca, 4 en Teruel y 8 en Zaragoza-. Dentro de estos criterios, el sistema 
ofrece dentro del campo «tipología» las opciones de: bodega industrial, chimenea industrial, chimenea, electrometalúrgicas, fábricas de cartón, fábricas de azúcar, fábrica de explosivos, industria de materiales cerámicos (inmuebles), mataderos y plantas embotelladoras. No existe, por tanto, ninguna opción que permita seleccionar algún criterio relacionado con la producción energética. Los resultados de esta búsqueda quedan reflejados en la Tabla V.

Tabla V. Resultado de la búsqueda bajo criterio de 'Inmueble Industrial' según tipología en el catálogo de la Dirección General de Cultura y Patrimonio.

\begin{tabular}{|c|c|c|c|}
\hline $\begin{array}{l}\text { DENOMINACIÓN DEL } \\
\text { BIEN INDUSTRIAL }\end{array}$ & $\begin{array}{l}\text { LOCALIZACIÓN } \\
\text { (PROVINCIA) }\end{array}$ & TiPOLOGía & $\begin{array}{l}\text { CATEGORÍA DE } \\
\text { PROTECCIÓN }\end{array}$ \\
\hline $\begin{array}{l}\text { Tolvas del cargadero de mi- } \\
\text { neral y nave de clasificación y } \\
\text { cribado }\end{array}$ & Ojos Negros (Teruel) & $\begin{array}{l}\text { Planta embotella- } \\
\text { dora }\end{array}$ & $\begin{array}{l}\text { Bien catalogado y de } \\
\text { interés local }\end{array}$ \\
\hline $\begin{array}{l}\text { Antiguo matadero municipal } \\
\text { de Zaragoza }\end{array}$ & Zaragoza (Zaragoza) & Matadero & Bien catalogado \\
\hline $\begin{array}{l}\text { Antigua fábrica de cartonaje } \\
\text { en C/Escoriaza y Fabro }\end{array}$ & Zaragoza (Zaragoza) & Fábrica de cartón & Bien catalogado \\
\hline Molinos de pólvora & Villafeliche (Zaragoza) & $\begin{array}{l}\begin{array}{l}\text { Fábrica de explo- } \\
\text { sivos }\end{array} \\
\text { sives }\end{array}$ & $\begin{array}{l}\text { Bien de interés } \\
\text { cultural }\end{array}$ \\
\hline $\begin{array}{l}\text { Bodega Cerdán y bodega Mo- } \\
\text { rales }\end{array}$ & $\begin{array}{l}\text { Almonacid de la Sierra } \\
\text { (Zaragoza) }\end{array}$ & Bodega industrial & Bien catalogado \\
\hline $\begin{array}{l}\text { Centro cultural del Antiguo } \\
\text { Matadero }\end{array}$ & Huesca (Huesca) & Matadero & Bien catalogado \\
\hline $\begin{array}{l}\text { Antigua fábrica azucarera de } \\
\text { Nuestra Señora de las Mer- } \\
\text { cedes }\end{array}$ & Alagón (Zaragoza) & Fábrica de azúcar & Bien catalogado \\
\hline $\begin{array}{l}\text { Chimenea de la Resinera del } \\
\text { Carmen }\end{array}$ & Teruel (Teruel) & \begin{tabular}{|l|} 
Chimenea indus- \\
trial
\end{tabular} & Bien catalogado \\
\hline Harinera de Monegros & Sariñena (Huesca) & No disponible & Bien catalogado \\
\hline $\begin{array}{l}\text { Puente giratorio para rever- } \\
\text { sión de locomotoras de la es- } \\
\text { tación de ferrocarril de Teruel }\end{array}$ & Teruel (Teruel) & No disponible & Bien catalogado \\
\hline $\begin{array}{l}\text { Antigua fábrica Azucarera La- } \\
\text { bradora }\end{array}$ & Calatayud (Zaragoza) & Fábrica de azúcar & Bien catalogado \\
\hline $\begin{array}{l}\text { Chimenea de la antigua fábri- } \\
\text { ca de sulfuro }\end{array}$ & Caspe (Zaragoza) & Chimeneas & $\begin{array}{l}\text { Monumento de inte- } \\
\text { rés local }\end{array}$ \\
\hline $\begin{array}{l}\text { Colección de vehículos de la } \\
\text { antigua empresa Carde y Es- } \\
\text { coriaza S.A. }\end{array}$ & Zaragoza (Zaragoza) & $\begin{array}{l}\text { Electrometalúr- } \\
\text { gica }\end{array}$ & Bien catalogado \\
\hline $\begin{array}{l}\text { Instalaciones alfareras del } \\
\text { barrio de las Ollerías de San } \\
\text { Julián }\end{array}$ & Teruel (Teruel) & $\begin{array}{l}\text { Industria de ma- } \\
\text { teriales cerámicos } \\
\text { (inmueble) }\end{array}$ & Bien catalogado \\
\hline
\end{tabular}

Fuente: elaboración propia según datos del catálogo de la

Dirección General de Cultura y Patrimonio de Aragón. 
Como puede observarse en las tablas, la mayor parte de los resultados están relacionados con los sectores agroalimentarios, mineros o de comunicaciones y no aparece ninguno relativo al subsector de generación energética. Igualmente, la búsqueda bajo criterios de «mueble» en el campo «tipo de bien» ni siquiera ofrece la posibilidad de seleccionar «industrial» en el campo «Categoría».

Por último, y centrándonos en el sector de la producción energética, la tercera y última búsqueda consistió en introducir en el campo de búsqueda los siguientes criterios: "central eléctrica», «central hidroeléctrica» y «central térmica». Ninguno de ellos arroja resultados. El único elemento relacionado con la producción eléctrica que el sistema nos ofrece es el Museo de la Electricidad de Murillo de Gallego (Huesca) inaugurado en 1995 - y actualmente abierto - por Luis Gallego Coiduras, bisnieto del fundador de la central eléctrica construida en la localidad en el año 1900 y que dejó de funcionar en 1975. Este museo se instaló en la antigua harinera de la localidad y en él se expone parte de la maquinaria de la central eléctrica. ${ }^{46}$ Se trata de un buen ejemplo de reutilización de un espacio industrial - la harinera - para conservar y difundir los restos muebles de la central eléctrica, todo ello bajo iniciativa privada.

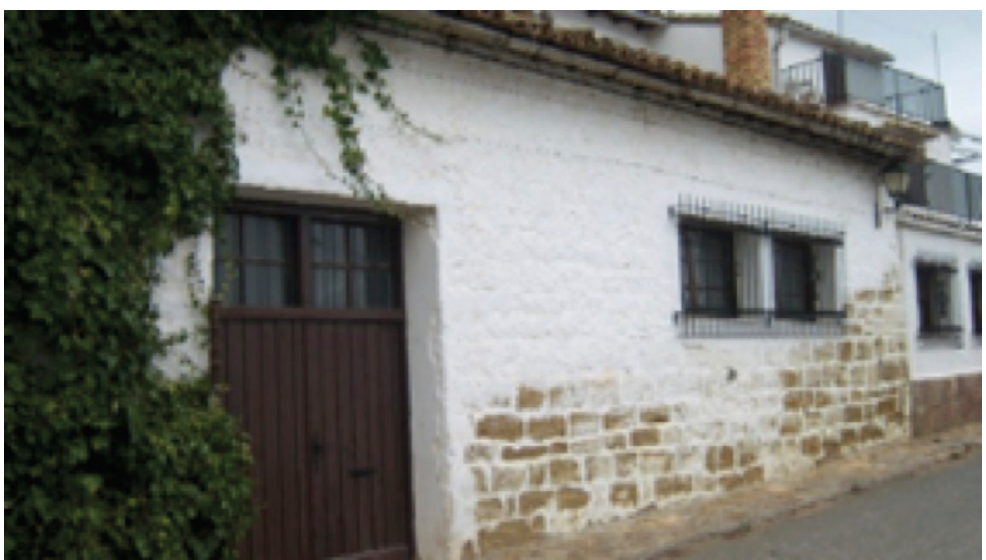

Imagen 13. Museo de la electricidad de Murillo de Gállego (Zaragoza).

Foto del autor.

46 Para más información sobre el Museo de la Electricidad de Murillo de Gallego consúltese su ficha en la base de datos de la Dirección General de Patrimonio: $<\mathrm{http}: /$ www.patrimonioculturaldearagon.es/ museos/museo-de-la-electricidad-murillo-de-gallego > [Consulta: 02-01-2020] 
Para reforzar los resultados anteriores, abandonamos el catálogo de la Dirección General de Cultura y Patrimonio del Gobierno de Aragón y usamos el registro SIPCA para realizar nueve búsquedas avanzadas combinando los campos «Clasificación» y seleccionando «arquitectura industrial», «tipo de bien» y, de nuevo, seleccionando «central eléctrica, central hidroeléctrica o central térmica» y el campo "protección jurídica» bajo los criterios de «bien de interés cultural, bien catalogado o bien inventariado» ofreciendo los resultados recogidos en la Tabla VI.

Tabla VI. Resultado de la búsqueda bajo el criterio de 'Central eléctrica, central térmica o central hidroeléctrica' en el SIPCA.

\begin{tabular}{|l|l|l|l|}
\hline \multicolumn{1}{|c|}{$\begin{array}{c}\text { TIPO DEL BIEN } \\
\text { INDUSTRIAL }\end{array}$} & $\begin{array}{c}\text { BIEN DE INTERÉS } \\
\text { CULTURAL }\end{array}$ & BIEN CATALOGADO & BIEN INVENTARIADO \\
\hline Central eléctrica & Sin resultados & Sin resultados & Sin resultados \\
\hline Central hidroeléctrica & Sin resultados & Sin resultados & Sin resultados \\
\hline Central térmica & Sin resultados & Sin resultados & Sin resultados \\
\hline
\end{tabular}

Fuente: elaboración propia según datos del SIPCA.

En consonancia con los datos ofrecidos por el catálogo de la Dirección General de Patrimonio, no existen actualmente en Aragón restos industriales del sector de la generación de energía que posean algún tipo de protección jurídica patrimonial. Pero aún se puede ahondar más en esta problemática particular de la comunidad aragonesa si levantamos la mirada hacia otras autonomías en las que sí se han preservado vestigios relacionados con la producción energética atendiendo a factores como la importancia de los avances tecnológicos que supusieron o los impactos positivos que generaron en los lugares donde se instalaron. Dicha protección ha tenido en cuenta, además, el contexto histórico en el que se sitúa el resto, el encuadre y la preservación de su localización geográfica, defendiéndolos especialmente ante iniciativas de crecimiento urbano.

Iniciar un estudio en profundidad sobre estructuras industriales de generación energética protegidas en otras comunidades autónomas, así como analizar los fundamentos de la protección jurídica que les asiste excedería, sin duda, los límites de este trabajo. No obstante, sirvan como ejemplo la planta de gas de San Sebastián ${ }^{47}$ (Guipúzcoa) y la de El Salto ${ }^{48}$ (Córdoba) que

47 Puede ampliarse mucha más información de esta estructura en el Catálogo del Departamento de Cultura y Política Lingüística del Gobierno Vasco.

48 Puede consultarse al respecto el Catálogo General de Patrimonio Histórico Andaluz. 
gozan de protección patrimonial $-\mathrm{y}$ un estado de conservación envidiable como puede observarse en las imágenes correspondientes - desde los años 2002 y 2003 respectivamente, cuando en Aragón tan apenas se estaban finalizando los trabajos de inventariado inicial de los restos industriales.

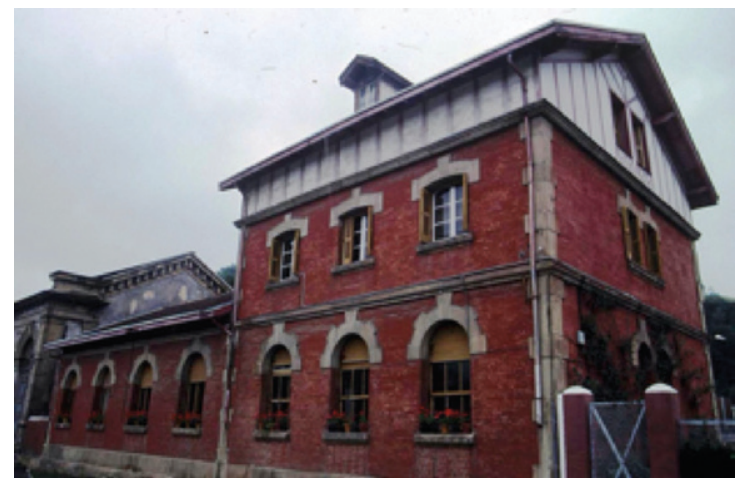

Imagen 14. Fábrica municipal de gas de San Sebastián (Gipuzkoa).

Fuente: Catálogo del Departamento de Cultura y Política Lingüística del Gobierno Vasco.

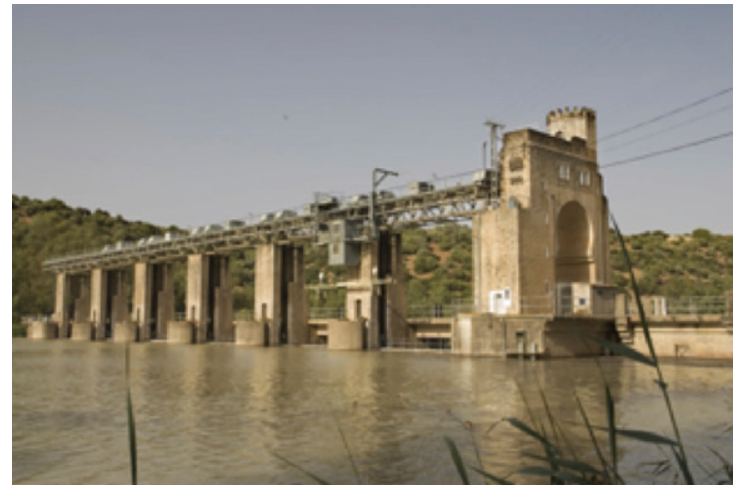

Imagen 15. Instalaciones de la central eléctrica de El Salto en el municipio de El Carpio (Córdoba). Fuente: <https://es.wikipedia.org/wiki/Presa_El_Salto\#/media/Archivo:IAPH_ Central_El_Salto.jpg>

\section{Conclusiones}

Llegados a este punto podemos extraer una serie de conclusiones. En primer lugar, encontramos que la disciplina encargada del estudio y 
preservación de los vestigios industriales es la arqueología industrial. En Aragón esta disciplina, junto con la concienciación en cuanto a la preservación de los restos industriales, surgió de una manera tardía con respecto a otros lugares, como el País Vasco, donde ya se desarrollaban tareas de inventariado antes incluso de que Aragón poseyera un marco jurídico efectivo que tuviera como objeto el patrimonio cultural. Este hecho ha provocado, sin duda, la destrucción de muchos paisajes industriales, como puede ser el Arrabal zaragozano, demolido gravemente a finales de los años 90 bajo criterios de crecimiento urbano, tan agresivo con el Patrimonio industrial próximo a los núcleos de población. En este sentido, se coincide con Asunción Urgel Masip cuando indica que en «Zaragoza se derribaba cuando ya había bienes industriales declarados Patrimonio de la Humanidad y experiencias de rehabilitación en Europa y en España». ${ }^{49}$

En segundo lugar, que el sector de la producción energética en Aragón mantuvo una importante presencia en el panorama nacional y potenció el proceso industrializador en aquella comunidad autónoma. Además de ello, los dos modelos de generación energética mayoritarios - hidroelectricidad y térmica - perviven en la actualidad, aunque, debido a los problemas medioambientales y de gestión de los elementos combustibles, la generación térmica cede terreno claramente ante energías más sostenibles. Las plantas energéticas que surgieron desde finales del siglo xix hasta la actualidad han supuesto nuevas configuraciones de los paisajes geográficos, nuevas relaciones comerciales y, en muchos casos, movimientos demográficos en menor o mayor escala.

En tercer lugar, se concluye que en Aragón los bienes culturales inventariados (los incluidos en el SIPCA, con y sin protección y de cualquier tipo) son, cuantitativamente hablando, mucho mayores que los bienes que poseen algún tipo de protección (los registrados en el catálogo de la Dirección General de Cultura y Patrimonio), representando estos últimos un bajo porcentaje (en torno al 18\%). ${ }^{50}$ Además, dentro de los restos protegidos, el resultado de vestigios relacionados con la arquitectura industrial o

49 Asunción Urgel Masip, «Ocasiones perdidas en Aragón o lo que pudo haber sido», en María Pilar Biel Ibáñez (coord.), Jornadas de patrimonio industrial y la obra pública de Zaragoza, Zaragoza, Gobierno de Aragón, 2007, pp. 75-101.

50 Teniendo en cuenta las más de 15000 fichas de patrimonio arquitectónico del registro SIPCA frente a las 2775 que se encuentran en el Catálogo de la Dirección General de Cultura y Patrimonio del Gobierno de Aragón. 
los inmuebles industriales es muy escaso: apenas 14 entradas de las $2775,{ }^{51}$ lo que representa un porcentaje inferior al $1 \%$.

En cuarto y último lugar concluimos que, a pesar de su importancia en el pasado social y económico aragonés, el Patrimonio industrial relacionado con el sector de la generación de energía no tiene representación alguna dentro de los bienes culturales protegidos. Esto implica que estos vestigios industriales permanecen en el más absoluto desamparo institucional, dejando su destino en manos de la inevitable destrucción debida al paso del tiempo. En Aragón se encuentran casos especialmente significativos y graves, como la central térmica de Aliaga, bello y mastodóntico vestigio industrial que, en el presente, permanece en un oscuro abandono. $\mathrm{O}$ también la central térmica de Teruel (Andorra) que pese a estar actualmente (junio de 2020) en funcionamiento, su cierre es inminente, debiendo comenzar a trabajar en torno a sus posibilidades de conservación, de reutilización y de preservación del medio natural en el que ha estado inmersa durante décadas.

Contra este deterioro constante de este patrimonio pugnan las asociaciones ciudadanas, reivindicando acciones y promoviendo usos diversos muy relacionados con el turismo o facetas artísticas como fotografía o video- que mantengan viva la esperanza de una recuperación de estos espacios industriales.

Finalmente, todo lo anterior lleva a plantear diversas cuestiones. ¿Por qué los vestigios aragoneses de la generación de energía no tienen protección alguna a pesar de la importancia de su pasado? ¿Por qué otras comunidades autónomas sí que desarrollaron hace décadas estudios y acciones que llevaron a proteger vestigios similares? Y, quizá el asunto más preocupante de cara a un futuro muy cercano es ¿̇se posee en Aragón una planificación viable - social y económicamente - ante el surgimiento inminente de nuevos vestigios industriales, como la planta térmica de Andorra? Son múltiples interrogantes de difícil respuesta, aunque en todas ellas aparece, sin duda, la falta de una concienciación real en cuanto a la necesidad de recuperar estos vestigios. En este sentido, es precisa la sinergia de tres actores; por un lado, los poderes públicos encargados de dirigir, proteger y vigilar la conservación y reutilización digna del patrimonio. Por otro lado, las entidades privadas

51 Se debe señalar aquí que la categoría de transportes y estaciones de ferrocarril no se incluyen en la categoría de restos industriales. No obstante, dichos restos son igualmente escasos. En la búsqueda bajo criterios de tipología como «Estación de ferrocarril» únicamente aparecen cuatro entradas. 
que fueron o continúan siendo propietarias de las estructuras y que, tras extraer un importante rédito económico, procedieron al cierre de las plantas productoras sin plantear opciones viables ni para el resto material ni para las gentes del lugar, contrayendo así una deuda social con las comarcas en las que se situaron. Por último, los colectivos sociales que, hastiados de observar cómo se destruye el patrimonio industrial, se muestran cada vez más activos, no estando dispuestos a dejar caer en el abandono y en el olvido una parte importante de nuestra historia más reciente.

\section{REFERENCIAS}

\section{Referencias bibliográficas}

Álvarez Areces, Miguel Ángel, 1995, Arqueología industrial. El pasado por venir. Gijón, CICEES.

Aracil Martí, Rafael, 1982, «La investigación en Arqueología industrial.» En I Jornadas sobre la protección y revalorización del Patrimonio industrial. Bilbao, Departamento de Cultura del Gobierno Vasco: 15-24.

Biel Ibá̃̃̃z, María Pilar, 1994, «¿Conservamos o adaptamos el patrimonio?», Artigrama, 11, 1994-95: 495-500.

Biel IbáÑez, María Pilar, 2004, Zaragoza y la industrialización: la arquitectura industrial en la capital aragonesa entre 1875-1936. Zaragoza, Institución Fernando El Católico.

Biel IbáÑ̃z, María Pilar, 2007, «El Patrimonio industrial en Aragón. Situación actual», en María Pilar Biel Ibáñez, coord., Jornadas de patrimonio industrial y la obra pública de Zaragoza. Zaragoza, Gobierno de Aragón. 255-274.

Biel Ibáñez, María Pilar y Francisco Javier Jiménez Zorzo, 2005, coords., Patrimonio industrial en la provincia de Zaragoza: Valdejalón. Zaragoza, Institución Fernando El Católico.

Biescas Ferrer, José Antonio, 1977, Introducción a la economía de la región aragonesa. Zaragoza, Alcrudo.

Germán Zubero, Luis, 1991, «El desarrollo de la industria eléctrica en Aragón (1893-1935)» En Atlas de Historia de Aragón, núm. 94. Zaragoza, Institución Fernando El Católico.

Germán Zubero, Luis, 2012, Historia económica del Aragón contemporáneo. Zaragoza, PUZ.

IzARD I Llorens, Miguel, 1982, «Arqueología, dependencia y subdesarrollo: el caso catalán.» En I Jornadas sobre la protección y revalorización del patrimonio industrial. Bilbao, Departamento de Cultura del Gobierno Vasco: 114-122. 
Jiménez Zorzo, Francisco Javier, 1985, Arqueología industrial en Zaragoza: la fábrica de fundición Averly. Zaragoza, Universidad de Zaragoza, Memoria de Licenciatura.

JimÉnez Zorzo, Francisco Javier, 1987, La industrialización en Aragón. La fundición Averly de Zaragoza. Zaragoza, Gobierno de Aragón.

Jiménez Zorzo, Francisco Javier, 1992, Arqueología industrial en Aragón: Arte, Industria y Sociedad (1850-1936) Zaaragoza, Universidad de Zaragoza, Tesis Doctoral.

Laborda Yneva, José y otros, 2000, Arqueología industrial en Aragón. Zaragoza, Edelvives.

Parra de Mas, Santiago, 1999, «El ferrocarril Zaragoza-Canfranc.» En María Ángeles Magallón Botaya, coord., Caminos y comunicaciones en Aragón. Zaragoza, Institución Fernando El Católico: 367-386.

Pétriz Borau, José Manuel y Javier Domínguez Hernández, 2000, Arqueología industrial en la provincia de Zaragoza. Zaragoza, ed. de los autores.

Querol Fernández, María Ángeles, 2012, Manual de gestión del patrimonio cultural. Madrid, Akal.

Raistrik, Arthur, 1972, Industrial Archaeology. Suffolk, Eyre Methuen.

URgel Masip, Asunción, 2007, «Ocasiones perdidas en Aragón o lo que pudo haber sido.» En María Pilar Biel Ibáñez, coord., Jornadas de patrimonio industrial y la obra pública de Zaragoza, Zaragoza, Gobierno de Aragón: 75-101.

Zárate Martín, Manuel Antonio y María Teresa Rubio Benito, 2011, Paisaje, sociedad y cultura en geografía bumana. Madrid, Ramón Areces.

\section{Webgrafía y otras referencias}

Asociación Pública para la Defensa del Patrimonio Aragonés (APUDEPA) $<$ https://apudepa.com/>

Blog «Cerrado por abandono» <https://cerradoporabandono.wordpress.com/>

Catálogo del Departamento de Cultura y Política Lingüística del Gobierno Vasco. $<$ http://www.euskadi.eus/web01-apintegr/es/y47aIntegraWar/IBConsultaController/ficha ConsultaBusqueda/4586>

Catálogo General del Patrimonio Histórico Andaluz: <https://www.juntadeandalucia.es organismos/culturaypatrimoniohistorico/areas/bienes-culturales/catalogopha.html>

Comité Internacional para la Conservación del Patrimonio Industrial (TICCIH): $<$ http://ticcih.org/>

Comité Internacional para la Conservación del Patrimonio Industrial (TICCIH) división española: $<$ http://ticcih.es/>

Constitución Española: <https://www.boe.es/buscar/doc.php?id=BOE A-197831229> 
Dirección General de Cultura y Patrimonio de Aragón: <http://www.patrimonioculturaldearagon.es/direccion-general-de-patrimonio-cultural>

ENDESA. Mapa de centrales productoras de energía: <https://www.endesa.com/ es/mapa-centrales.html>

Ley 3/1999, de 10 de marzo de Patrimonio Cultural Aragonés: <https://www.boe. es/buscar/act.php?id=BOE-A-1999-8270\&tn=2\&p=20160203>

Ley 16/1985, de 25 de junio de Patrimonio Histórico Español: <https://www.boe. es/buscar/act.php?id=BOE-A-1985-12534>

Ministerio de Cultura y Deporte de España: <http://www.culturaydeporte.gob. es/planes-nacionales/inicio-recuperar.html>

Sistema de Información del Patrimonio Cultural Aragonés (SIPCA): <http:// www.sipca.es/>

Sistema de Información del Patrimonio Cultural Vasco: $<$ http://www.euskadi.eus/ web01-apintegr/es/y47aIntegraWar/inicio?locale=es>

Sindicato de Iniciativa y Propaganda de Aragón (SIPA). Oficina situada dentro del Colegio de Arquitectos de Zaragoza, en calle San Voto, 7. 